\title{
Intercritical annealing of cold-rolled ferrite-pearlite steel: microstructure evolutions and phase transformation kinetics
}

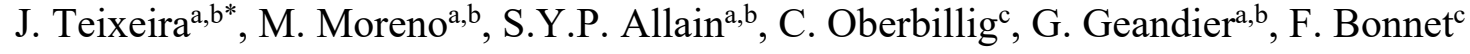 \\ anstitut Jean Lamour, UMR 7198 CNRS - Univ. Lorraine, Nancy, France. \\ bLaboratory of Excellence "Design of Alloy Metals for Low-mass Structures" (DAMAS), Univ. Lorraine. \\ ${ }^{\mathrm{c} A r c e l o r M i t t a l}$ Maizières Research SA, Automotive Products Research Center, Maizières les Metz, France.
}

\begin{abstract}
The manufacturing of Dual-Phase steels includes as a crucial step the annealing of a cold-rolled ferrite-pearlite $(\mathrm{F} / \mathrm{P})$ microstructure, which involves numerous and interacting metallurgical mechanisms, namely recovery/recrystallization of ferrite, globularization, manganese enrichment, coarsening of cementite and finally austenite transformation. Present study focuses on the austenite transformation considering its interaction with the ferrite recrystallization and the influence of the chemical composition of the cementite. The behavior of a cold-rolled F/P microstructure is studied at three heating rates to induce weak and strong interactions between the mechanisms, in particular using post mortem microstructure observations but also in situ High Energy X-Ray Diffraction experiments on a synchrotron beamline.

Slow heating leads to a necklace austenite distribution whereas fast heating conducts to a banded topology. This particular microstructure morphogenesis is explained by the presence of numerous intergranular (or isolated) carbides inside the ferrite matrix, inherited from the hot-rolling. Thermokinetic analysis accounting for the cementite composition shows that the pearlite islands transformation necessarily involves the partition of substitutional elements. Conversely, the dissolving isolated carbides undergo a partition/partitionless transition on heating. After the dissolution of the cementite, a final ferrite/austenite transformation takes place. The phase transformation kinetics increases with increasing heating rates, despite the thermal-activated nature of the austenite growth process. This is interpreted thanks to kinetic simulations with DICTRA software, which allow to analyze the austenite growth regimes involving or not the partition of the alloying elements.
\end{abstract}

\section{Keywords}

Austenite transformation, Dual-Phase steels, intercritical annealing, HEXRD, Cementite dissolution, DICTRA simulations

*Corresponding author

Julien Teixeira

Institut Jean Lamour

CNRS - Université de Lorraine

Campus Artem

2, allée André Guinier

BP 50840

F-54011 NANCY CEDEX

FRANCE

tel +33372742690

fax +33372742401

julien.teixeira@univ-lorraine.fr

Author's email addresses:

Marc Moreno:m moreno@hotmail.fr

S.Y.P. Allain: sebastien.allain@univ-lorraine.fr

C. Oberbillig: carla.oberbillig@arcelormittal.com

G. Geandier: guillaume.geandier@univ-lorraine.fr

F. Bonnet : frederic.bonnet $@$ arcelormittal.com 


\section{Introduction}

2 Dual-Phase (DP) steels are largely employed in the automotive industry for their excellent

3 strength / ductility trade-off and their weight reduction potential [1-7]. DP steels have a

4 composite microstructure composed of carbon-rich martensite islands embedded in a matrix

5 of softer ferrite [1] and occasionally containing bainite [8]. The tensile properties (yield

6 strength, ultimate tensile strength, uniform elongation) depend strongly on the volume

7 fraction of the martensite [9-11]. Its three-dimensional features, i.e. the spatial and

8 morphological distribution of the phases, also influence the fracture properties and the

9 resistance to damage. For example, banded structures of elongated martensite islands aligned

10 in the rolling direction have a negative impact on the damage properties and on the local

11 ductility [12-15]. Conversely, the tensile properties depend weakly on the spatial organization

12 of the phases [12].

13 Precise control of the properties requires thus to understand how the microstructures are

14 formed during the thermomechanical processing of DP steels. The sequence of treatments

15 starts with a hot-rolling operation in the full-austenite domain. After a cooling sequence

16 during the coiling operation, a cold-rolling step at room temperature is applied in addition to

17 obtain thinner products of interest for automotive construction. The crucial step is the final

18 intercritical annealing [16-18]: a partial austenite transformation takes place in the biphasic

19 ferrite+austenite domain of stability; during the final cooling, the austenite transforms

20 progressively again to ferrite at high temperature, then in bainite and finally into martensite.

21 Hence, the final martensite microstructure (previously austenite) is largely inherited from the

22 intercritical annealing. Many investigations considered the austenite transformation occurring

23 during this step, focusing on two main features: the austenite morphogenesis and the phase

24 transformation kinetics. 
26 Important parameter of the intercritical annealing is the heating rate up to the soaking temperature. Slow heating leads to a necklace morphology of the austenite, whereas fast heating leads to a banded morphology, with strong impact on the mechanical behavior [1921]. This morphological transition is mostly specific to cold-rolled ferrite-pearlite initial microstructures [2,22-27]. Except in [16,27,28], it does not occur for other initial microstructures such as hot-rolled ferrite-pearlite $[23,25]$ or mixtures including bainite and/or martensite [2]. Faster heating leads to faster austenite transformation kinetics [2,22-25,28], despite the thermal-activated nature of the nucleation-growth process and whatever the initial microstructure. After fast heating, the final fraction of austenite can overcome the value expected from thermodynamics [24,29]. The local chemical compositions in the final microstructure may remain out of equilibrium. The transformation kinetics can follow different stages involving or not the partition of the alloying elements [1,30,31].

These complex evolutions come from the interactions of the austenite transformation with other metallurgical processes. In the case of an initial cold-rolled ferrite-pearlite microstructure, the cementite and the ferrite matrix undergo several phenomena during the heating and before the start of the austenite transformation [32,33]. The cementite carbides undergo fragmentation, spheroidization and coarsening; these processes are accelerated by the defects introduced by the cold-rolling [34-40]. This modifies the size and the spatial distribution of the carbides and thus of the initial nucleation sites and the carbon sources for the austenite. The chemical composition of the carbides also evolves during heating; enrichment in Mn and Cr stabilizes the carbides, slows-down their dissolution and hence the austenite transformation [41-48]. Actually, the initial composition of the carbides before the annealing treatment already depends on the metallurgical history of the hot band (so-called inheritance effects) [49]. 
51 As for the ferrite matrix, it becomes highly defected after the cold-rolling. It undergoes on heating recovery and then recrystallization processes [50-52]. During slow heating, the ferrite recrystallization is complete before the start of the austenite transformation, which takes place, except for the pearlitic ferrite, inside a fully recrystallized microstructure. ("Weak" interaction between austenite transformation and ferrite recrystallization as the mechanisms occur sequentially). In the case of slow heating, there is a general agreement in literature regarding the austenite morphogenesis. The necklace morphology comes from the nucleation and growth of the austenite at the boundaries of the large and equiaxed ferrite grains. Point of disagreement concerns the nature of the nucleation sites: either intergranular carbide, or “empty" ferrite grain boundaries. During fast heating, the austenite transformation and the ferrite recrystallization take place simultaneously (strong interaction). The heating rate has to be sufficiently fast to shift the ferrite recrystallization above the Acl temperature. The critical heating rate depends on the steel composition, the amount of cold-rolling reduction and the initial microstructure, as shown e.g. by processing maps produced by some authors $[2,53]$. In this latter case, there is no general agreement regarding how the austenite transformation and the ferrite recrystallization interact.

There are several interpretations to explain the faster transformation kinetics during faster heating. Some studies report that the presence of non-recrystallized and recovered ferrite would accelerate the austenite transformation $[2,24,27,29]$. The defects in the deformed ferrite grains would provide nucleation sites, fast diffusion paths and increased driving force. On the contrary, other studies do not report that the deformed ferrite would transform particularly fast

72 [26]. According to [25], the austenite nucleation would even be difficult at the moving boundaries of the recrystallizing ferrite. According to other studies, the faster austenite 
increase the density of austenite nuclei $[23,25]$. In return several studies report that newly formed austenite slows down the ferrite recrystallization [22,24,29,51,54], for instance by consuming potential nucleation sites [22].

The origin of the transition from the necklace to the banded morphology is also discussed. According to [27], the austenite would inherit the initial elongated shape of the deformed ferrite grains. The recrystallizing ferrite grains would also adopt this shape according to [27]. Other studies $[24,29]$ mention the influence of Mn microsegregation bands stimulating the austenite transformation and slowing-down the ferrite recrystallization. Li et al. [26] mention the influence of the distribution of the carbides in the initial microstructure. This distribution would be modified when recrystallization processes occur. According to [23,25], faster heating shifts the austenite nucleation to the pearlite islands to the detriment of the slowertransforming ferrite matrix. The pearlite islands would thereby confer their initial elongated and banded shape (due to the cold-rolling) to the forming austenite.

Hence, despite a number of studies, the transition from the necklace to the banded morphology remains to be understood, as well as the faster transformation kinetics during faster heating. The present study aims to investigate further these issues by several means. A steel with composition Fe-0.1C-1.9Mn-0.2Cr-0.2Si wt.\% with cold-rolled ferrite-pearlite initial microstructure is considered. A new experimental approach [55] is utilized to establish in situ by synchrotron high energy XRD the austenite transformation and the ferrite recovery/recrystallization global kinetics, in one single experiment. Three heating rates before isothermal annealing at $800^{\circ} \mathrm{C}$ are applied, fast $\left(30\right.$ and $\left.100^{\circ} \mathrm{C} . \mathrm{s}^{-1}\right)$ and slow $\left(3^{\circ} \mathrm{C} . \mathrm{s}^{-1}\right)$ to induce strong or weak interactions. Only three annealing treatments are thus considered, but the microstructure evolutions are observed in detail by systematic SEM characterizations, focusing on the interactions of the austenite transformation with the ferrite recrystallization and the carbides ripening. Particular emphasis is also put on the influence of the isolated 
cementite carbides on the austenite transformation and morphogenesis. Their spatial and size

101 distribution evolutions are established thanks to quantitative metallography, before and after

102 ferrite recrystallization. Enrichments of the cementite carbides in Mn during annealing were

103 already established in this steel by TEM-EDS in [49]. On this basis and from quantifications

104 of the initial microstructure, DICTRA simulations are setup in order to understand the

105 influence of the heating rate on the austenite transformation kinetics.

1062 Studied material, experimental techniques, thermodynamic calculations

\section{$107 \quad 2.1 \quad$ Studied material}

108 The composition of the studied steel is given in Table 1. It is a low-carbon steel without

109 microalloying elements $(\mathrm{Ti}, \mathrm{Nb}, \mathrm{V}, \mathrm{B})$. The material has been provided by ArcelorMittal

110 either in hot-rolled or in cold-rolled state, as flat sheets of respectively $3 \mathrm{~mm}$ and $1.2 \mathrm{~mm}$

111 thickness. The industrial hot-rolling process consists of a reheating of the slabs at ca. $1200^{\circ} \mathrm{C}$,

112 a finish rolling at $900^{\circ} \mathrm{C}$ and a coiling at about $550^{\circ} \mathrm{C}$ after fast cooling on a run-out table.

113 After coiling, cooling rate of the hot-rolled coils is about $20^{\circ} \mathrm{C} / \mathrm{h}$, from $550^{\circ} \mathrm{C}$ down to room

114 temperature. In hot bands, the resulting microstructure is a mixture of ferrite and pearlite. The

115 reduction ratio of the cold-rolling is $60 \%$; this corresponds to a mean deformation of $106 \%$ in

116 bulk. As the pearlite shows a higher flow stress than the ferrite, the deformation is even higher

117 in the ferritic matrix. According to micromechanical models [56,57], the deformation in

118 pearlite and ferrite is respectively equal to $67 \%$ and $119 \%$ accounting for their respective

119 volume fractions (values are presented in Section 3.1.1).

120 The steel presents micro-segregations bands resulting from the processing. According to

121 WDS measurements (spatial resolution ca. $1 \mu \mathrm{m}$ ) in the cold-rolled state, the $\mathrm{Mn}$

122 concentration along the whole thickness of the sheet ranges between 1.84 and $2.02 \mathrm{wt} . \%$ The

123 chromium concentration ranges between 0.17 and $0.22 \mathrm{wt} . \%$ and the concentration of the 
124 silicon ranges between 0.20 and $0.24 \mathrm{wt} . \%$. The average spacing between the

125 microsegregation bands is of the order $4.5 \mu \mathrm{m}$.

\begin{tabular}{lllll}
\hline & C & Mn & Cr & Si \\
\hline weight fraction (\%) & 0.1 & 1.91 & 0.195 & 0.205 \\
\hline u-fraction (\%) & & 1.94 & 0.209 & 0.407
\end{tabular}

126

127

128

129

130

131

132 distributions (initial hot-rolled or cold-rolled state or heating below Ac1). A Dino etchant (40

Table 1. Chemical composition of the investigated steel. u-fractions correspond to the chemical compositions with respect to the sole substitutional elements.

\subsection{Annealing schedules}

The model heat treatment, which is applied to the cold-rolled material, comprises two steps: the cold-rolled samples are heated from room temperature to the annealing temperature of $800^{\circ} \mathrm{C}$, followed by $10 \mathrm{~min}$ holding before helium quenching. Three constant heating rates are considered: $3^{\circ} \mathrm{C} . \mathrm{s}^{-1}, 30^{\circ} \mathrm{C} \cdot \mathrm{s}^{-1}$ and $100^{\circ} \mathrm{C} \cdot \mathrm{s}^{-1}$. Both lowest heating rates are representative of present-day annealing capabilities by most steelmakers.

Interrupted treatments between $\mathrm{Ac} 1$ and $800^{\circ} \mathrm{C}$ and spaced out by $10^{\circ} \mathrm{C}$ are done to follow in detail the development of the austenite microstructure and the ferrite recrystallization. Except for the XRD in situ experiments (Section 2.7), the heat treatments have been performed with an in-house Rapid-Cycle Dilatometer. Heating is achieved by four light bulbs of $1500 \mathrm{~W}$ and cooling is achieved by helium blowing.

\subsection{Metallographic preparation}

Samples prepared for SEM observations were coated with epoxy resin (sagittal cut), polished with silicate grid paper down to $1 \mu \mathrm{m}$ and finished with a colloidal silica suspension solution. Before etching, an ultra-sonic cleaning bath in warm methanol ( $\sim 30 \mathrm{~min}$.) permits to remove the fine colloidal silica particles and to avoid pollution of the samples. Two types of etching have been applied. A Picral solution at $2 \%$ was used to characterize the carbides sizes and $\mathrm{mL}$ of distilled water, $100 \mathrm{~mL}$ of hydrogen peroxide (30\%), $4 \mathrm{~g}$ of oxalic acid, $2 \mathrm{~mL}$ of 
147 sulfuric acid and $1.5 \mathrm{~mL}$ of hydrofluoric acid) was used to reveal the carbides and the

148 martensite (previously austenite) after heating above Ac1 and quench. The Dino etchant also

149 permits to reveal the grain and sub-grain boundaries in the ferrite.

\subsection{SEM microstructural observations}

151 Two SEMs have been used in this study. The carbides microstructures were characterized

152 (heating below Ac1, Picral etching) with a Philips XL-30 FEG-SEM. The austenite

153 microstructure evolutions (heating above Ac1, Dino etching) were followed with a JEOL

154 JSM-IT300 Tungsten SEM. All observations were made in secondary electron mode. The

155 micrographs were acquired at quarter thickness of the sheets to avoid skin effects and possible

156 macro-segregation in the center. The microstructures have been observed only in the samples

157 heated at $3^{\circ} \mathrm{C} \cdot \mathrm{s}^{-1}$ and $30^{\circ} \mathrm{C} \cdot \mathrm{s}^{-1}$.

$\begin{array}{lll}158 & 2.5 & \text { Image analysis }\end{array}$

159 Mean pearlite island and ferrite grain sizes were measured using the intercept method defined 160 by the ASTM standard E112-96 procedure [58]. The fractions of austenite or pearlite islands 161 were quantified following the ASTM E65 standard [59]. Fractions of austenite were measured 162 after Dino etching on SEM micrographs by applying a threshold in grey levels. Fractions of 163 recrystallized ferrite were estimated following the point counting method for the $30^{\circ} \mathrm{C}^{-1} \mathrm{~s}^{-1}$

164 heating rate and by EBSD analysis based Grain Orientation Spread (GOS) parameter at $3^{\circ} \mathrm{C} . \mathrm{s}^{-}$ $165{ }^{1}[60]$.

166 ImageJ software was used to characterize the carbides morphologies, sizes and densities. First

167 operation is a binarization of the SEM micrograph obtained after Picral etching. Despite the

168 good initial contrast, the definition of a simple threshold was not sufficient. Classical routines

169 such as opening, eroding or closing led to biases. Specific routines were developed in

170 particular to deal with the presence of grain boundaries. The reader is referred to [61] for a 
171 detailed presentation. The true cementite particles sizes distribution was determined by

172 applying the Johnson-Saltikov stereological correction [62], as detailed in [63], which also

173 reviews and compares other existing correction methods.

\section{$174 \quad 2.6 \quad$ Transmission electron microscopy}

175 The chemical composition of the carbides was measured by EDXS in TEM. The specimens

176 were ground parallel to the initial faces of the flat products down to a thickness of $60 \mu \mathrm{m}$ with

177 grinding papers, to avoid both the decarburized layer close to the surface, and

178 macrosegregations near the center. $3 \mathrm{~mm}$ diameter foils were punched out and then drilled by

179 electropolishing using a perchloric-acetic acid solution at $18^{\circ} \mathrm{C}$ with a tension of $30 \mathrm{~V}$. A

180 JEOL TEM microscope was operated at $200 \mathrm{kV}$ (ARM FEG). Composition measurements

181 were performed with a BRUKER XFlash EDXS Silicon Drift Detector with a resolution of

$182127 \mathrm{eV}$ and a collector plate of $30 \mathrm{~mm}^{2}$. The probe size for these measurements is about $1 \mathrm{~nm}$.

183 As the detection of light chemical species like carbon is not possible by EDXS because of the

184 energy resolution and pollution issues, only the major substitutional species were considered:

$185 \mathrm{Fe}, \mathrm{Mn}, \mathrm{Cr}$ and Si. By using standard statistical techniques, the relative error in the measured

186 concentrations does not exceed 5\%.

187 For each investigated condition, about 5 cementite particles have been observed in detail by

188 measuring composition profiles with a probe size of ca. $1 \mathrm{~nm}$. Average compositions were

189 also measured in about 20 other carbides. All particles were located in pearlite islands (not at

190 ferrite grain boundaries). It was not possible to determine with certainty whether or not the

191 particles were located in microsegregation bands. More details on the TEM sample

192 preparation and observations can be found in reference [49], which is focused on the

193 evolutions of the carbides compositions. 


\subsection{High Energy X-Ray Diffraction}

196 The HEXRD experiments were carried out at the Deutsches Electronen-Synchrotron on the

197 PETRA III P07 beamline (DESY, Hamburg, Germany). It was operated with a powder

198 diffraction setup in transmission, similar to the one used in reference [64]. The samples were

199 lamellar with dimensions $10 \times 5 \times 1.2 \mathrm{~mm}^{3}$. Like for other analyses, these were cut down

200 from the industrial steel sheet. The long direction $(10 \mathrm{~mm})$ corresponds to the rolling

201 direction. The thickness $(1.2 \mathrm{~mm})$ direction is normal to the plane of the sheet. The X-Ray

202 beam crosses the sample along its thickness. The size of the high energy monochromatic

203 beam (energy $100 \mathrm{keV}$, wavelength $0.012398 \mathrm{~nm}$ ) was $400 \times 400 \mu \mathrm{m}^{2}$ broad, which means

204 that approximatively 50,000 grains were scanned through the thickness $(1.2 \mathrm{~mm})$ of the

205 sample (but the number of diffracting grains in Bragg reflection condition is lower).

206 Calibration was performed using Fit2D software (v18, ESRF, Grenoble, France) $[65,66]$ to

207 adjust the sample to detector distance and correct the detector tilts using LaB6 powder. The

208 distance was set to $1.251 \mathrm{~m}$ to observe fully the 6 first diffraction rings of ferrite. The

209 diffraction patterns can be recorded at a high rate $(10 \mathrm{~Hz})$ on a PerkinElmer 2-D plate detector

210 thanks to the brilliance of the line and the energy used. The thermal cycle was performed in a

211 modified Bähr 805 A/D (TAinstruments) dilatometer. The sample could not be rotated during

212 the experiments, but it will be seen that powder diffraction conditions could be achieved,

213 despite the strong texture introduced by the cold rolling.

214 The continuous heating step was recorded in fast acquisition mode $(10 \mathrm{~Hz})$. Slow mode was

215 re-activated after $60 \mathrm{~s}$ holding at $800^{\circ} \mathrm{C}$ until the end of the treatment. In slow mode, patterns

216 are acquired every $3 \mathrm{~s}(\sim 0,33 \mathrm{~Hz})$. The temperature was measured in real time with a K-type

217 thermocouple spot welded at the surface of the sample, just above the volume crossed by the

218 beam. During heating in fast mode, the uncertainty in the temperature is estimated as $\Delta \mathrm{T}=$

$219 \pm 0.1 \mathrm{x} \mathrm{HR}$, where HR is the heating rate and $0.1 \mathrm{~s}$ is the duration of an acquisition in fast 
mode. For instance, uncertainty due to the acquisition method in temperature during heating

221 at $30^{\circ} \mathrm{C} \cdot \mathrm{s}^{-1}$ is $\pm 3^{\circ} \mathrm{C}$.

222 A Rietveld analysis [67] was conducted to determine the phase transformation kinetics.

223 Pictures of Debye-Scherrer (DS) rings were integrated using the Fit2D software. The 1D

224 diffraction pattern was then refined with Fullprof software (V2.05, ILL, Grenoble, France) in 225 a $2 \theta$ range from $2.70^{\circ}$ to $8.70^{\circ}$ using Pseudo-Voigt functions [68]. Only two phases have been

226 considered (ferrite and austenite); peaks due to cementite could be detected, but these peaks

227 were too small to allow a proper quantification. The minimum detectable austenite mass

228 fraction is about $2 \%$ with such a procedure. This value corresponds to the accuracy of the

229 phase fraction measurement [64].

230 A new method has been introduced recently to track in situ by HEXRD the recrystallization

231 kinetics, together with the phase transformation kinetics [55]. This method is related to the

232 presence of individual spots of intensity inside the Debye-Scherrer diffraction rings, which

233 are ascribed to the new recrystallizing ferrite grains. By counting the number of diffraction

234 spots, it is possible to estimate the recrystallization kinetics. The accuracy of the method has

235 to be improved, but first comparisons with recrystallized fractions determined by EBSD are

236 satisfactory.

\section{$237 \quad 2.8 \quad$ Thermodynamic and kinetic simulations}

238 The thermodynamic calculations were performed with Thermocalc software and the TCFE7

239 database. The kinetics simulations were performed with DICTRA software with TCFE7 and

240 MOBFE2 databases. 


\subsection{Microstructure evolutions before the austenite transformation}

\subsubsection{Hot-rolled microstructure}

244 Figure 1 shows SEM micrographs of the as received industrial hot-rolled (HR) and cold-

245 rolled (CR) microstructures. The micrographs were binarized with the procedure described in

246 Section 2.5. After HR and subsequent cooling, the microstructure consists of polygonal ferrite

247 and pearlite islands containing lamellar cementite carbides. The cementite is often not

248 perfectly lamellar and presents a more rounded shape near the pearlite island boundaries. The

249 proeutectoid ferrite grains are equiaxed and their mean radius is estimated to $5 \mu \mathrm{m}$. The

250 pearlite islands have a volume fraction estimated to $16 \%$. Observations at a larger scale (not

251 shown here) show that the pearlite islands are often organized in bands parallel to the rolling

252 direction. This topology is due in part to the Mn microsegregations; it is known that

253 proeutectoid ferrite forms preferentially in Mn-depleted zones during the coiling. But in many

254 other observations, the pearlite islands are more randomly distributed.

255 Important feature of the HR microstructure is the presence of a large number of isolated

256 cementite carbides located mainly at the boundaries of the proeutectoid ferrite grains and

257 outside the pearlite islands. Most of these carbides have an elongated shape along the ferrite

258 grain boundaries (GBs), but some are more equiaxed. Despite their low volume fraction, the

259 isolated carbides contain about one third of the carbon of the steel (64\%). This proportion is

260 deduced from the volume fraction of the pearlite islands $(16 \%)$, which is lower than a value of

$26125 \%$, expected from a thermodynamic analysis of pearlite transformation detailed in [49]. It

262 will be seen in the following that these isolated carbides will play a major role during the

263 austenite transformation even if presence of intergranular carbides has rarely been reported

$264[33,40,69-72]$. According to [69-71], these are formed during slow cooling before the pearlite 
transformation. During the proeutectoid ferrite transformation, some carbon-rich regions of austenite would be trapped between growing ferrite grains and would then decompose to one or several cementite carbides and ferrite. Another mechanism assuming the super-saturation in carbon of the ferrite was proposed more recently in [72].

Figure 1. SEM micrographs treated by image analysis representative of the hot-rolled (a) and cold-rolled (b) microstructures. The ferrite is represented in black, the pearlitic cementite in white and the isolated carbides in red.

\subsubsection{Effects of the cold-rolling}

After the cold rolling (Figure 1b), the ferrite grains and the pearlite islands are flattened and elongated in the rolling direction; both are ca. $3 \mu \mathrm{m}$ thick, while the lengths are more scattered. Inside the pearlite islands, some of the cementite lamellae remain unmodified, but most of these are now fragmented. As for the isolated carbides, those which were elongated before the $\mathrm{CR}$ were fragmented during the deformation, generating clusters of carbides aligned parallel to the rolling direction and distributed at the boundaries of the deformed ferrite grains (see also [26]). There are also some intra-granular carbides inside the ferrite grains, but their number is very small.

\subsubsection{Microstructure evolutions during heating to Ac1}

For both heating rates, 3 and $30^{\circ} \mathrm{C} \cdot \mathrm{s}^{-1}$, the microstructure was observed (Figure 2) after heating up to $700^{\circ} \mathrm{C}$ and $720^{\circ} \mathrm{C}$ respectively. Close to the $\mathrm{Ac} 1$ temperature (respectively $710^{\circ} \mathrm{C}$ and $720^{\circ} \mathrm{C}$ according to microstructure observations, Section 3.4), these temperatures are representative of the initial microstructure at the start of the austenite transformation. Before this stage, different microstructural evolutions occur during the heating up to Ac1: the 
recovery and recrystallization of the ferrite; the fragmentation of the cementite carbides. The

290 latter also undergo enrichment in $\mathrm{Cr}$ and Mn during the slow heating at $3^{\circ} \mathrm{C} \cdot \mathrm{s}^{-1}[49,61]$.

291 Regarding the recrystallization, the evolutions are different for both heating rates. As shown

292 in Figure 2a, the ferrite matrix is almost fully recrystallized after the slow heating. The

293 recrystallized ferrite grains are nearly equiaxed and have an average size of $6 \mu \mathrm{m}$. Very few

294 ferrite grains remain unrecrystallized, whereas former pearlite islands are never recrystallized.

295 Conversely, after the fast heating, the ferrite recrystallization has almost not started (Figure

2962 b) at $720^{\circ} \mathrm{C}$. Most ferrite grains kept their initial elongated shape resulting from the cold

297 rolling. They contain a large number of subgrains with a typical size of $0.5 \mu \mathrm{m}$, which result

298 from recovery processes starting at $380^{\circ} \mathrm{C}$ [55]. Hence, a transition from full recrystallization

299 before austenite transformation to no recrystallization occurs between heating rates $3^{\circ} \mathrm{C}^{-1} \mathrm{~s}^{-1}$

300 and $30^{\circ} \mathrm{C} \cdot \mathrm{s}^{-1}$. The order of magnitude of the critical heating rate for this transition between

301 two modes of interaction (the so-called "weak" and "strong" interactions) is in accordance

302 with previous studies on similar systems [2,28,73]. Detailed experimental and modelling

303 study of recrystallization is presented in [55,74]. Regarding the pearlitic ferrite, no significant

304 recrystallization occurs during both slow and fast heating, as confirmed by EBSD analyses.

305 As for the cementite carbides, different effects of the heating rate are observed for the

306 pearlitic cementite and for the isolated carbides. The cementite carbides inside the pearlite

307 islands undergo the same evolutions for both heating rates: they become more fragmented,

308 leading to a more spheroidal shape and to a large increase of the particles density. They

309 probably also undergo coarsening. Both fragmentation and coarsening phenomena are

310 accelerated by the prior severe deformation [34,35], especially, for the fragmentation, by the

311 defects introduced inside the cementite [36-39]. The pearlitic cementite carbides reach the

312 same average equivalent radius, $75 \mathrm{~nm}$, for both heating rates (Table 2). It should be

313 mentioned that the lamellar carbides (i.e. not yet fragmented) were excluded from the size 
314 measurements, which makes difficult to interpret in detail the size and densities evolutions.

315 More measurements can be found in reference [61].

316 In contrast with the pearlitic cementite, the evolution of the isolated carbides (outside the

317 pearlite islands) shows a dependence on the heating rate. During slow heating, the ferrite

318 recrystallization, which has time to occur, modifies the size and the spatial distribution of the

319 isolated cementite carbides with respect to the ferrite grain boundaries. Some carbides get

320 trapped inside the recrystallized ferrite grains, while other carbides are localized at the

321 boundaries of the ferrite grains. The latter tend to be bigger than the intragranular carbides

322 (this could not be quantified), probably because of the faster diffusion at the grain boundaries.

323 The mechanisms by which the recrystallization can modify the carbides distribution are

324 discussed in Section 4.1.3. After the fast heating, the isolated carbides keep their initial

325 distribution in the CR microstructure, mostly in the form of elongated clusters, parallel to the

326 rolling direction and located at the boundaries of the deformed ferrite grains. There are almost

327 no carbides inside the deformed ferrite grains (Figure 2d). The isolated carbides are larger in

328 average after slow heating than after fast heating (Table 2), because of the larger size of the

329 carbides located at the boundaries of the recrystallized ferrite grains. More measurements can

330 also be found in reference [74].

332 Figure 2. SEM micrographs representative of the microstructure after heating to a,c,e) $700^{\circ} \mathrm{C}$ at $3^{\circ} \mathrm{C} . \mathrm{s}^{-1} ; \mathrm{b}, \mathrm{d}, \mathrm{f}$ )

$333720^{\circ} \mathrm{C}$ at $30^{\circ} \mathrm{C} \cdot \mathrm{s}^{-1}$. Figures $\mathrm{c}$ and $\mathrm{d}$ correspond to views at higher magnification of a and $\mathrm{b}$. Figures e and $\mathrm{f}$ have 334 been threshold to reveal carbide microstructures in both cases (carbides in bright contrast). 


\subsection{Ferrite recrystallization kinetics}

337 As presented in [55], the in situ HEXRD experiments also allow to estimate the kinetics of the 338 ferrite recrystallization. Figure 3 shows the recrystallized fraction as a function of the 339 temperature during the heating stage, as determined both from HEXRD and from SEM. 340 Above Ac1, relative fractions are plotted, that is, the ratio of the recrystallized fraction over 341 the fraction of remaining ferrite. It can be seen that the method based on HEXRD tends to 342 overestimate the recrystallization kinetics, compared to the image analysis of SEM 343 micrographs. The latter are actually accurate only for the heating rate $3^{\circ} \mathrm{C} \cdot \mathrm{s}^{-1}$, for which 344 EBSD was employed to draw Grain Orientation Spread maps. Conversely at $30^{\circ} \mathrm{C}^{-\mathrm{s}^{-1}}$, the 345 estimates of recrystallized fractions are based on observation of SEM micrographs after 346 chemical etching. Nevertheless, SEM and HEXRD observations are in agreement regarding 347 the temperature range at which the ferrite recrystallization occurs, as a function of the heating 348 rate. Figure 3. Fraction of recrystallized ferrite as a function of the temperature during heating at 3,30 or $100^{\circ} \mathrm{C} \cdot \mathrm{s}^{-1}$. Dots: HEXRD, squares: SEM at $30^{\circ} \mathrm{C} \cdot \mathrm{s}^{-1}$ or EBSD at $3^{\circ} \mathrm{C} \cdot \mathrm{s}^{-1}$. (In the SEM analyses, the pearlitic ferrite was excluded).

352 Focusing on the kinetics obtained from HEXRD, at $3^{\circ} \mathrm{C} \cdot \mathrm{s}^{-1}$, the ferrite recrystallization starts 353 at ca. $670^{\circ} \mathrm{C}$ and is almost complete at $710^{\circ} \mathrm{C}$, the $\mathrm{Ac} 1$ temperature, as will be seen in next 354 sections. At $30^{\circ} \mathrm{C} \cdot \mathrm{s}^{-1}$, the ferrite recrystallization starts near $730^{\circ} \mathrm{C}$ and finishes at ca. $780^{\circ} \mathrm{C}$. 355 This is in good agreement with the microstructure observations near the Ac1 temperature 356 (Figure 2). At $100^{\circ} \mathrm{C} \cdot \mathrm{s}^{-1}$, the recrystallization kinetics is shifted to higher temperatures. It 357 finishes in less than $6 \mathrm{~s}$ during the isothermal hold at $800^{\circ} \mathrm{C}$. Thus, as aimed when designing 358 the treatments, the slow heating at $3^{\circ} \mathrm{C} \cdot \mathrm{s}^{-1}$ permits (almost) full decoupling of the respective 359 kinetics of ferrite recrystallization and austenite transformation, while faster heating at $30^{\circ} \mathrm{C}^{-\mathrm{s}^{-}}$ $360{ }^{1}$ and $100^{\circ} \mathrm{C} \cdot \mathrm{s}^{-1}$ will give rise to strong interactions, as will be seen in the next sections. 


\subsection{Austenite transformation: kinetics}

362 The austenite transformation kinetics was measured in situ by HEXRD with the method 363 presented in Section 2.7. Figure 4 shows the Debye-Scherrer (DS) rings recorded at $650^{\circ} \mathrm{C}$

364 and $800^{\circ} \mathrm{C}$ during the heating at $3^{\circ} \mathrm{C} \cdot \mathrm{s}^{-1}$, along with the integrated intensity- $2 \theta$ profiles.

365 Additional profile at $760^{\circ} \mathrm{C}$ is added to illustrate the start of the austenite transformation.

366 Continuous DS rings and the expected relative intensities of the diffraction peaks are obtained 367 thanks to the large number of diffracting grains, leading to powder diffraction conditions. At $368650^{\circ} \mathrm{C}$, only visible DS rings are those of the ferrite. At $800^{\circ} \mathrm{C}$, these become weaker because 369 of the lower ferrite mass fraction, while austenite rings are clearly visible. The cementite 370 peaks are visible only at high magnification of the I-2 $\theta$ profiles. The cementite mass fraction 371 could not be quantified by our Rietveld method.

372 Figure 5a shows the austenite fraction as a function of the temperature during the heating stage. According to the HEXRD, the Ac1 temperature is equal to $710^{\circ} \mathrm{C}, 740^{\circ} \mathrm{C}$ and $746^{\circ} \mathrm{C}$

374 respectively at $3^{\circ} \mathrm{C} . \mathrm{s}^{-1}, 30^{\circ} \mathrm{C} . \mathrm{s}^{-1}$ and $100^{\circ} \mathrm{C} . \mathrm{s}^{-1}$. (The first detection of austenite by HEXRD 375 corresponds to the beginning of the curve). At $3^{\circ} \mathrm{C} \cdot \mathrm{s}^{-1}$ and $30^{\circ} \mathrm{C} \cdot \mathrm{s}^{-1}$, the austenite fraction 376 follows a similar evolution as a function of the temperature, with an upward shift of about $37710^{\circ} \mathrm{C}$ at $30^{\circ} \mathrm{C} \cdot \mathrm{s}^{-1}$. Hence, the phase transformation kinetics is about ten times faster at $30^{\circ} \mathrm{C} \cdot \mathrm{s}^{-1}$ 378 than at $3^{\circ} \mathrm{C} \cdot \mathrm{s}^{-1}$. Both kinetics show two stages: a first sluggish stage up to about $740^{\circ} \mathrm{C}$ and $379750^{\circ} \mathrm{C}$ at $3^{\circ} \mathrm{C} \cdot \mathrm{s}^{-1}$ and $30^{\circ} \mathrm{C} . \mathrm{s}^{-1}$ respectively, followed by a fast kinetics. During the first stage, 380 the fraction of austenite remains below a few percent, but the austenite is clearly detected by 381 the HEXRD. The kinetics at $100^{\circ} \mathrm{C} \cdot \mathrm{s}^{-1}$ exhibits one single stage; the fraction of austenite at 382 any given temperature is almost always higher than at $3^{\circ} \mathrm{C} \cdot \mathrm{s}^{-1}$ and $30^{\circ} \mathrm{C} \cdot \mathrm{s}^{-1}$. This shows that 383 the kinetics is the fastest for this heating rate. One has though to mention that at $100^{\circ} \mathrm{C} \cdot \mathrm{s}^{-1}$, the 384 experimental uncertainty on the temperature is equal to $\pm 15^{\circ} \mathrm{C}$. For all heating rates, the 385 austenite fraction remains far below the orthoequilibrium (OE) value, up to $800^{\circ} \mathrm{C}$. 
The austenite fraction evolution during the isothermal annealing at $800^{\circ} \mathrm{C}$ is plotted in Figure

3875 b. For all heating rates, the transformation kinetics firstly slows down quickly; the austenite 388 fraction then progressively stabilizes to reach some plateau. The higher the heating rate, the 389 faster the kinetics and the higher the final fraction of austenite. At $30^{\circ} \mathrm{C} \cdot \mathrm{s}^{-1}$ and $100^{\circ} \mathrm{C} \cdot \mathrm{s}^{-1}$, this 390 final fraction exceeds the value expected from overall thermodynamic equilibrium. Similar 391 overshoot above the equilibrium at higher heating rates was also reported in $[2,24,26,27,29]$.

Figure 4. 2D Debye-Scherrer rings recorded at 650 and $800^{\circ} \mathrm{C}$ during heating at $3^{\circ} \mathrm{C} \cdot \mathrm{s}^{-1}$. Intensity-2 $\theta$ profiles

Figure 5. Austenite mass fraction as a function of a) temperature during heating; b) time during isothermal annealing at $800^{\circ} \mathrm{C}$ (zoom on first stages in the insert). Time scale starts at the beginning of the isothermal annealing in b). The dots indicate the austenite fraction at the start of the isothermal annealing.

\subsection{Austenite transformation: microstructure evolutions above Ac1}

402 The nucleation sites of the austenite and the different stages of its morphogenesis are 403 identified here with SEM observations of the microstructure after interrupted treatments

404 (Section 2.2). The most relevant observations are summarized here, but additional 405 observations are reported in the discussion on the austenite morphogenesis (Section 4.1).

\section{$406 \quad 3.4 .1$ Slow heating, $3^{\circ}{\mathrm{C} . \mathrm{s}^{-1}}^{-1}$}

407 Figure 6 shows SEM micrographs of the microstructure at the main stages of the austenite 408 transformation during the slow heating. The ferrite matrix is almost fully recrystallized when 409 the austenite transformation starts as already discussed and shown in Figure 4a. Outside the 
pearlite islands, the microstructure mostly consists of large and equiaxed ferrite grains. The

411 nucleation of the austenite starts between $700^{\circ} \mathrm{C}$ and $710^{\circ} \mathrm{C}$, at isolated carbides located at the

412 boundaries of these ferrite grains (Figure 6a). Second main nucleation sites are the boundaries

413 of the pearlite islands. Nevertheless, nucleation starts later on these sites, between 710 and

$414720^{\circ} \mathrm{C}$. This first detection of austenite is in good agreement with the Ac1 determined by

$415 \operatorname{HEXRD}\left(710^{\circ} \mathrm{C}\right)$.

$416 \mathrm{Up}$ to $730^{\circ} \mathrm{C}$, the growth of the austenite grains remains sluggish and limited to the

417 boundaries of the ferrite grains or the pearlite islands (Figure 6b). Austenite fraction remains

418 below $1.5 \% \mathrm{~m}$ (XRD). The austenite morphology is either spheroidal (especially when it

419 nucleated at triple junctions involving or not a pearlite island) or elongated, as a result of the

420 preferential austenite growth along the grain boundaries. At ca. $740^{\circ} \mathrm{C}$, the pearlite islands

421 start to transform quickly to austenite; their transformation is almost complete at $750^{\circ} \mathrm{C}$

422 (Figure 6c). Newly formed austenite grains inherit the width of the pearlite islands, typically 3

$423 \mu \mathrm{m}$, and their high carbon concentration, 1.78 at.\%. Hereafter, the austenite grains stemming

424 from the pearlite islands will be referred to as carbon-rich austenite (CRA) grains. On further

425 heating, the CRA grains grow towards the surrounding ferrite. The pearlite islands

426 transformation corresponds to a marked increase of the rate of austenite formation (Figure

427 5a). The austenite grains which nucleated on the isolated carbides grow more slowly along the

428 proeutectoid ferrite grain boundaries. Nucleation on the isolated carbides is progressive and

429 the sizes of the austenite grains nucleated on these sites are thus scattered. The austenite

430 eventually decorates the ferrite grain boundaries, giving rise to the necklace morphology.

431 At $800^{\circ} \mathrm{C}$, the necklace morphology is clearly observable; most of the ferrite grain boundaries

432 are decorated by the austenite. The austenite films actually percolated before, at ca. $780^{\circ} \mathrm{C}$

433 (corresponding micrograph is not shown here). The austenite films observable at $800^{\circ} \mathrm{C}$ grew

434 into the interior of the ferrite grains and reached a thickness of ca. $500 \mathrm{~nm}$. Besides, the 
austenite grains stemming from the pearlite islands achieve a banded morphology, because of the initial distribution of the pearlite islands.

Figure 6. SEM observations (Dino etching) of the microstructure after heating at $3^{\circ} \mathrm{C} \cdot \mathrm{s}^{-1}$ followed by quench up to a) $710^{\circ} \mathrm{C}$; b) $730^{\circ} \mathrm{C}$; c) $750^{\circ} \mathrm{C}$; d) $800^{\circ} \mathrm{C}$. In a), the arrows show the first grains of austenite.

\subsubsection{Fast heating, $30^{\circ} \mathrm{C} . \mathrm{s}^{-1}$}

During the fast heating, the austenite transformation starts in a microstructure which is almost non-recrystallized, contrary to the case of the slow heating. As shown in Figure $7 \mathrm{a}$ at $740^{\circ} \mathrm{C}$, most of the ferrite grains are still deformed and filled with subgrains; only few recrystallized ferrite grains can be observed. Despite the different initial microstructure, the nucleation sites of the austenite remain the same as during slow heating. The austenite nucleates first on isolated carbides between 710 and $720^{\circ} \mathrm{C}$ (high-magnification micrographs are not shown here) and then at the boundaries of the pearlite islands (between 720 and $730^{\circ} \mathrm{C}$ ). The Ac1 temperature determined by HEXRD is higher $\left(740^{\circ} \mathrm{C}\right)$, but for a heating rate of $30^{\circ} \mathrm{C} . \mathrm{s}^{-1}$, this corresponds to $1 \mathrm{~s}$ during the experiment. What differs compared to the slow heating is the distribution of the austenite nucleation sites outside the pearlite islands. The isolated carbides are located at the boundaries of the deformed and elongated ferrite grains. The austenite grains nucleating on these sites grow equiaxially exclusively; in contrast with the slow heating, preferential growth along the grain boundaries is rarely observed, as shown for instance at $740^{\circ} \mathrm{C}$ in Figure $7 \mathrm{a}$.

Like in the case of the slow heating, the pearlite islands start to transform at a sluggish rate before an acceleration at about $750^{\circ} \mathrm{C}$, whereas the austenite grains nucleating on the isolated carbides nucleate more progressively and grow more slowly. The pearlite islands transform in 
most part in a narrow temperature range, between 750 and $760^{\circ} \mathrm{C}$ (Figure $7 \mathrm{~b}$ ). This temperature range is slightly shifted to higher temperatures $\left(\mathrm{ca} .10^{\circ} \mathrm{C}\right.$ ), compared to the slow heating. When the pearlite islands are fully transformed, significant recrystallization has still to take place (fraction of ferrite remaining to recrystallize depends on the experimental method, HEXRD or SEM, see Figure 3). This further recrystallization of the ferrite will contribute to the morphogenesis of the microstructure.

Figure 7. SEM observations (Dino etching) of the microstructure after heating at $30^{\circ} \mathrm{C} . \mathrm{s}^{-1}$ followed by quench up to a) $740^{\circ} \mathrm{C}$; b) $760^{\circ} \mathrm{C}$; c) $770^{\circ} \mathrm{C}$; d) $800^{\circ} \mathrm{C}$. The arrows indicate: first austenite grains in (a); alignments of austenite grains at the boundaries of elongated recrystallized ferrite grains in (c).

Upon further heating up to $800^{\circ} \mathrm{C}$, the microstructure undergoes simultaneous evolutions: the growth of the newly formed carbon-rich austenite (CRA) grains stemming from the pearlite islands, the nucleation and growth of the austenite grains from the isolated carbides and the recrystallization of the ferrite. All of the three processes contribute to form the banded morphology. The CRA grains grow into the surrounding ferrite matrix. Like for the slow heating, they reach at $800^{\circ} \mathrm{C}$ a banded morphology, which is inherited from the initial distribution of the pearlite islands. The austenite grains nucleated on the isolated carbides grow first equiaxially and then tend to impinge and to form alignments parallel to the rolling direction. Examples of such alignments are shown in Figure 7b. This distribution in bands comes from the layout of the isolated carbides in the initial microstructure, which is caused by the cold rolling. 
482 The recrystallizing ferrite grains reach a more elongated shape than during slow heating; their

483 length can reach $10 \mu \mathrm{m}$. This is the consequence of the concomitant austenite transformation,

484 because the ferrite recrystallization is confined inside the forming bands of austenite

485 (stemming from pearlite islands or from the isolated carbides). Thus, the new recrystallized

486 ferrite grains inherit the initial elongated shape of the deformed ferrite grains. Figure 7c

$487\left(770^{\circ} \mathrm{C}\right)$ shows several examples of elongated recrystallized ferrite grains. These are

488 surrounded by austenite grains emanating either from perlite islands or from isolated carbides.

489 Once the recrystallized ferrite grains have acquired an elongated shape, the austenite

490 continues to nucleate and grow at their boundaries, thereby reinforcing further the banded

491 topology of the microstructure. These combined phenomena lead to the banded morphology

492 of the austenite, which is clearly observable at $800^{\circ} \mathrm{C}$ (Figure $7 \mathrm{~d}$ ).

\section{$493 \quad 3.4 .3 \quad$ Isothermal annealing at $800^{\circ} \mathrm{C}$}

494 During isothermal annealing at $800^{\circ} \mathrm{C}$ for $10 \mathrm{~min}$., the austenite transformation progresses

495 further. As shown in Figure 5c, the austenite mass fraction increases from $47 \%$ to $81 \%$ after

496 heating at $3^{\circ} \mathrm{C} . \mathrm{s}^{-1}$, from $49 \%$ to $85 \%$ after heating at $30^{\circ} \mathrm{C} . \mathrm{s}^{-1}$ and from $56 \%$ to $89 \%$ at

$497100^{\circ} \mathrm{C} \cdot \mathrm{s}^{-1}$. This further growth of the austenite into the ferrite (originating from pearlite

498 islands or isolated carbides) is associated with a disappearance of the austenite topology

499 (Figure 8), which was initially either necklace or banded. The austenite distribution becomes

500 more homogeneous. This vanishing of the initial morphology is already observable after $60 \mathrm{~s}$

501 of isothermal hold (corresponding micrographs are not shown). After the isothermal annealing

502 for $600 \mathrm{~s}$, there is no clear difference between the microstructures corresponding respectively

503 to the slow and to the fast heating. In both cases, the smaller ferrite grains are fully consumed,

504 while the largest ones remain in the final microstructure. As for the kinetics characterizations,

505 which showed a marked slowdown of the kinetics after $60 \mathrm{~s}$ annealing (cf. Figure $5 \mathrm{~b}$ ), this

506 was confirmed by SEM micrographs. 
Figure 8. SEM observations (Dino etching) of the microstructure after heating up to $800^{\circ} \mathrm{C}$ and isothermal annealing for $600 \mathrm{~s}$. a) $3^{\circ} \mathrm{C} . \mathrm{s}^{-1}$; b) $30^{\circ} \mathrm{C} \cdot \mathrm{s}^{-1}$.

\section{Discussion}

\subsection{Austenite morphogenesis, banded or necklace}

\section{$513 \quad$ 4.1.1 Proposed mechanism}

514 As usually reported in literature, slow and fast heating lead respectively to necklace and

515 banded microstructures, which are established by different sequences schematized in Figure

516 9. During slow heating $\left(3^{\circ} \mathrm{C} \cdot \mathrm{s}^{-1}\right)$, the ferrite recrystallization is almost complete before the

517 start of the austenite transformation. At the Ac1 temperature, $700-710^{\circ} \mathrm{C}$, only few ferrite

518 remains unrecrystallized. The recrystallized ferrite grains have a size of ca. $6 \mu \mathrm{m}$ and an

519 equiaxed shape; many coarsened carbides are located at their boundaries because of the

520 recrystallization process. The austenite nucleates on these carbides and then grows

521 preferentially along the boundaries of the recrystallized ferrite grains, thereby forming the

522 necklace morphology. Meanwhile, the pearlite islands transform to carbon-rich austenite

523 (CRA) grains, which then grow towards the surrounding ferrite. The CRA grains have a

524 banded morphology because of the elongated shape of the initial pearlite islands (Figure 1b,

525 Figure 2a). The final topology of the microstructure is nevertheless dominated by the network

526 of Austenite Nucleated on isolated Carbides (ANC) covering the ferrite grains boundaries

527 (even if the respective fractions of ANC and CRA appears similar in the micrographs).

528 Indeed, the initial pearlite islands occupy only $16 \%$ of the volume fraction in the initial

529 microstructure. 
530 During fast heating $\left(30^{\circ} \mathrm{C} \cdot \mathrm{s}^{-1}\right)$, the recrystallization has almost not started at the Ac1

531 temperature $\left(710-720^{\circ} \mathrm{C}\right)$. On heating, the isolated carbides thus kept their initial distribution

532 resulting from the cold rolling. It consists of clusters aligned in the rolling direction and

533 located at the boundaries of the deformed ferrite grains. Alignments of austenite grains

534 nucleate on these carbides (ANC) and grow equiaxially. By impinging, these grains start to

535 form the banded morphology. Meanwhile, the transforming pearlite islands (CRA grains) also

536 contribute to form the banded topology. The concomitant ferrite recrystallization is now

537 confined between the forming bands of austenite, originating either from the isolated carbides

538 or from the pearlite islands. Hence during fast heating, the new recrystallized ferrite grains

539 acquire an elongated shape, thereby reinforcing the banded topology of the microstructure.

540 Finally, the last austenite grains nucleate at the boundaries of the elongated recrystallized

541 ferrite grains, thereby reinforcing further the morphology in bands.

542 The mechanism proposed above for the genesis of the necklace morphology during slow

543 heating is in agreement with the literature related to initial cold-rolled ferrite-pearlite

544 microstructures [2,24-27]. The nucleation of austenite at carbides located at recrystallized

545 ferrite grain boundaries is also clearly mentioned [24,26,27], except in [25]. Nevertheless, in

546 the latter study, these carbides are observable in the presented micrographs. Conversely, the

547 origin of the banded morphology has been interpreted differently [23-25,27]. As it is obtained

548 during fast heating, the austenite transformation takes place in the presence of non-

549 recrystallized ferrite grains. The point of disagreement concerns whether or not the latter

550 transform to austenite faster than the remaining of the ferrite matrix. The role of $\mathrm{Mn}$

551 microsegregation bands has also been considered. This is discussed in Sections 4.1.3 and

$552 \quad 4.1 .4$ 


\subsubsection{Influence of the isolated and intergranular carbides}

557 It comes out the preceding analysis that the "isolated carbides" distribution determines the 558 formation of either a necklace or a banded austenite microstructure. The isolated carbides are 559 those localized outside the pearlite islands, in the ferrite matrix (as presented in Section 3.1.1).

560 Among these carbides, only those located at ferrite grain boundaries or triple junctions

561 (intergranular carbides) play a significant role. As the austenite starts to nucleate and grow

562 from these sites, this determines the initial spatial distribution of the austenite and its further 563 morphogenesis. The same conclusion was reached, as far as we know, in only one previous 564 study, by Li et al. [26]. Minor differences concern what are the firstly activated nucleation 565 sites (the pearlite islands in [26]). In [26], intermediate heating rates were also investigated, 566 leading to an austenite microstructure intermediate between necklace and banded.

567 The role played by these carbides may seem unexpected at first sight, because of their low 568 volume fraction in the initial microstructure (see Figure 1). This is why these carbides are 569 frequently not considered in literature [33,40,69-72]. Despite their low volume fraction, the 570 isolated carbides contain (in the studied steel) about one third of the carbon. Hence, a similar 571 proportion of the austenite is expected to form from these carbides. Contrary to the case of the 572 pearlite islands, their spatial distribution with respect to the ferrite grain boundaries may 573 evolve during heating, depending on the heating rate, because of some interaction with the 574 ferrite recrystallization (see next section). Conversely, the pearlite islands and the austenite

575 resulting from their transformation keep a banded morphology whatever the heating rate.

576 However, the pearlite islands have an initial volume fraction equal to $16 \%$, which limits their 577 impact on the final microstructure. 
578 In order to confirm the role played by the isolated carbides, SEM observations were

579 conducted. Figure 10 shows some examples for a heating up to $740^{\circ} \mathrm{C}$ at $3^{\circ} \mathrm{C} \cdot \mathrm{s}^{-1}$. In most

580 cases, a carbide (white contrast) was observed as expected inside austenite grains forming

581 along planar ferrite grain boundaries. However, the presence of such carbide is not systematic.

582 Despite the absence of fully conclusive observations, the preferential nucleation of austenite

583 on isolated carbides is highly probable: combined with a ferrite grain boundary, the

584 intergranular cementite particles represent high-energy defects, which are favorable

585 heterogeneous nucleation sites for the austenite. The austenite grains then grow preferentially

586 in their vicinity, because the dissolving carbides provide a source of carbon. Several studies

587 also report that in presence of intergranular carbides, the austenite nucleates preferentially on

588 these sites $[26,27,30,32,33]$. When the austenite is reported to nucleate at "empty"

589 ferrite/ferrite grain boundaries [75-77], the considered microstructures do not include any

590 intergranular carbide.

591 The only other significant nucleation sites for the austenite are the intragranular carbides,

592 which are trapped inside recrystallized ferrite grains, mostly in the case of the slow heating.

593 Some examples can be seen in Figure 2. However, few austenite grains nucleated on these

594 sites; these grains grew slowly and always stabilized to a limited size (Figure 10a). Their slow

595 growth comes most likely from the bulk diffusion which is involved; their small size comes

596 from the absence of other neighboring carbon sources. Therefore, these intragranular austenite

597 grains contribute weakly to the austenite morphogenesis. In the case of the fast heating,

598 intragranular carbides were almost never observed. 
604 From our experimental observations, we have established in the studied steel that the main 605 influence of the ferrite recrystallization on the austenite morphogenesis is indirect, but 606 determining. During the slow heating, it modifies the spatial distribution of the isolated 607 carbides which are then located in large part at the boundaries of the recrystallized ferrite 608 grains. This is thought to be the origin of the necklace microstructure. These carbides are also 609 larger than in the initial microstructure. The detailed interactions between the recrystallizing 610 ferrite and the carbides are not clear from the literature. Straightforward reason for the larger 611 intergranular carbides sizes is that the presence of the grain boundary would accelerate the 612 diffusion and the coarsening processes. The large number of isolated carbides at the 613 boundaries of the recrystallized ferrite grains can be explained if the carbides impeded the 614 moving boundaries of the recrystallizing ferrite grains. According to [2,30], the boundaries of 615 the recrystallizing ferrite grains can in some cases overcome the pinning force of the carbides 616 and leave behind intragranular carbides, inside the new recrystallized ferrite grains. These 617 carbides would tend to dissolve to the benefit of those localized at the grain boundaries.

618 During the fast heating, the ferrite recrystallization has a different effect, which comes from 619 its interaction with the concomitant austenite transformation. As described previously, the 620 bands of transforming austenite tend to "channel" the ferrite recrystallization, which 621 reinforces the banded morphology. Same observation was reported in [24]. In return, the 622 ferrite recrystallization has an impact on the austenite morphogenesis. Alignments of austenite 623 grains form at the boundaries of elongated recrystallized ferrite grains (Figure 7c). Similar 624 observation was reported in [27].

625 Point of disagreement with some previous studies [24,27] is related to the rate of 626 transformation to austenite of the deformed and non-recrystallized ferrite grains. During fast 627 heating, this would explain the morphogenesis in bands according to these works. The 
austenite grains would acquire a banded morphology by inheriting the elongated shape of the deformed ferrite grains [27]. The fast transformation of the deformed ferrite grains is explained in $[24,27]$ by the energy stored inside and by the defects, which provide nucleation sites and fast diffusion paths. However, in present study, any faster transformation of the deformed ferrite could not be seen clearly from the microstructural observations. Further quantitative analysis of the microstructure would be necessary, as done for instance in [24].

Let us mention that in the latter study, the non-recrystallized ferrite grains contained a large number of intragranular cementite carbides. This may explain in part their fast transformation to austenite. Conversely in present study, the deformed ferrite grains were almost empty of any carbide (Section 3.1.3).

Let us mention that the development of the banded morphology was interpreted in $[25,27]$ without considering any influence of the deformed ferrite grains on the austenite transformation. For very fast heating rates, $100^{\circ} \mathrm{C} \cdot \mathrm{s}^{-1}$ in [25] and $140-693^{\circ} \mathrm{C} \cdot \mathrm{s}^{-1}$ in [27], the austenite transformation takes place exclusively from the pearlite islands, which confer their elongated shape to the austenite. In the ferrite matrix, the more sluggish austenite transformation has not enough time to occur. Hence, in these cases, the morphology in bands comes from the selection of the nucleation sites for kinetic reasons. This selection of austenite nucleation sites (pearlite vs. ferrite grain boundaries) was also been put into evidence in [23]. Such transition did not occur in present study because of the too slow heating rates considered.

\subsubsection{Influence of the Mn microsegregation bands}

The investigated steel contains manganese microsegregation bands (Mn bands) aligned with the rolling direction (Section 3.1.1). Although the range of Mn concentrations is low (1.8-2.0 wt.\% at quarter thickness, according to WDS) possible impact on the morphogenesis in bands during fast heating cannot be ruled out. No clear correlation could though be found between 
653 the spacing of the Mn bands (4.5 $\mu \mathrm{m}$ according to WDS) and of the austenite bands after fast 654 heating at $30^{\circ} \mathrm{C} \cdot \mathrm{s}^{-1}$, for instance up to $800^{\circ} \mathrm{C}$ (Figure $7 \mathrm{~d}$ ). The austenite bands are actually 655 scattered, which makes difficult to measure their spacing. In contrast, in [24] where a steel 656 with higher magnitude of Mn concentrations was considered, the bands of austenite were 657 better defined and more continuous.

658 More indirect impact of the Mn bands, could be to influence the distribution of the cementite 659 in the initial microstructure. In [24], it is reported that the Mn bands are spatially correlated 660 with a higher density of intragranular carbides, inside the deformed ferrite grains. In [2], it is 661 also mentioned that the pearlite in the initial microstructure tends to occupy the Mn-rich 662 regions. Weaker impact of the Mn bands on the initial pearlite distribution was found in 663 present study (Section 2.1). This may come again from the weak degree of Mn segregation in 664 the investigated steel.

665

666

\subsection{Austenite transformation kinetics}

\subsubsection{Kinetics stages; identification of two sub-systems}

669 For both heating rates $3^{\circ} \mathrm{C} . \mathrm{s}^{-1}$ and $30^{\circ} \mathrm{C} . \mathrm{s}^{-1}$, the austenite transformation starts at a sluggish 670 rate (Figure 5b), before a strong acceleration at about 740 and $750^{\circ} \mathrm{C}$ respectively. (The first 671 stage is less visible at $100^{\circ} \mathrm{C} \cdot \mathrm{s}^{-1}$, but this may come from the precision of the measurements).

672 This first stage corresponds to the slow growth of the first austenite grains, which nucleated 673 both at isolated carbides and at the boundaries of pearlite islands. The acceleration 674 corresponds clearly to the transformation of the pearlite islands, according to the SEM 675 micrographs (Section 3.4). The impact on the global kinetics is visible because the pearlite 676 islands transform simultaneously in a narrow temperature range of about $10^{\circ} \mathrm{C}$. In contrast, 
677 the austenite grains stemming from the carbides isolated in the ferrite matrix nucleate and

678 grow more progressively and more slowly. Their impact on the global kinetics is thus less

679 visible. Hence, two sub-systems behaving differently in terms of kinetics are identified: the

680 austenite stemming from the pearlite islands (carbon-rich austenite 'CRA'), or the isolated

681 carbides (austenite nucleated on carbides, 'ANC').

682 Conversely to previous studies which also considered an initial ferrite-pearlite microstructure

683 (e.g. [1,76]), there is no sharp transition from a fast regime of pearlite transformation followed

684 by a slower ferrite / austenite transformation. This is due to the isolated carbides, which

685 dissolve progressively, both before and after the pearlite islands transformation. Moreover, as

686 the pearlite islands occupy initially $16 \%$ of the volume fraction, their transformation does not

687 make increase drastically the austenite fraction (Figure 5b). Once the pearlite islands have

688 fully transformed at 750 or $760^{\circ} \mathrm{C}$, the austenite transformation goes on in both sub-systems,

689 without further identifiable kinetics stages.

690

$691 \quad$ 4.2.2 Influence of the heating rate

692 The faster the heating rate, the faster the austenite transformation kinetics, during both the

693 heating stage and the subsequent isothermal hold. During heating, the austenite

694 transformation is about ten times faster at $30^{\circ} \mathrm{C} . \mathrm{s}^{-1}$ than at $3^{\circ} \mathrm{C} . \mathrm{s}^{-1}$; it is even faster at $100^{\circ} \mathrm{C} . \mathrm{s}^{-1}$

695 (Section 3.3). These results from XRD are further confirmed by austenite fractions

696 determined by image analysis at $800^{\circ} \mathrm{C}: 49 \%$ at $3{ }^{\circ} \mathrm{C} . \mathrm{s}^{-1}, 49 \%$ at $30^{\circ} \mathrm{C} \cdot \mathrm{s}^{-1}$ and $47 \%$ at $100^{\circ} \mathrm{C} . \mathrm{s}^{-}$

697 1. Similar observation was done in previous studies regarding the isothermal annealing stage

$698[2,23-27,29]$. As for the heating stage, there is no clear agreement in the literature, but some

699 studies do also report faster transformation during faster heating (e.g. [2,24]). Three possible

700 origins of the faster kinetics are discussed in the following: the presence of non-recrystallized 
701 ferrite, the higher driving force linked with the faster heating and the faster growth of the austenite stemming from the pearlite islands. (The influence of kinetics regimes of austenite growth involving or not the partition of the alloying elements is treated separately in the next

\section{Section)}

According to some studies $[2,24,29]$, one possible origin of the faster austenite transformation during faster heating and/or subsequent holding is the presence of non-recrystallized ferrite grains, which would transform faster to austenite. In present study, this would explain the faster kinetics at $30^{\circ} \mathrm{C} . \mathrm{s}^{-1}$ than at $3^{\circ} \mathrm{C} . \mathrm{s}^{-1}$, because for the latter heating rate, the ferrite almost fully recrystallizes before reaching the Ac1 temperature. As mentioned in Section 4.1.3, faster transformation of the non-recrystallized ferrite is possible in the investigated steel, but further quantitative microstructural characterization would be necessary to confirm this. Let us mention that for both heating rates $30^{\circ} \mathrm{C} \cdot \mathrm{s}^{-1}$ and $100^{\circ} \mathrm{C} \cdot \mathrm{s}^{-1}$, the ferrite recrystallization is concomitant to the austenite transformation (Section 3.2). Hence, the faster austenite transformation kinetics at $100^{\circ} \mathrm{C} . \mathrm{s}^{-1}$ than $30^{\circ} \mathrm{C} . \mathrm{s}^{-1}$ can be less clearly interpreted by the presence of more non-recrystallized ferrite than when comparing heating rates $3^{\circ} \mathrm{C} . \mathrm{s}^{-1}$ and $30^{\circ} \mathrm{C} . \mathrm{s}^{-1}$. At least, accelerated growth in non- recrystallized ferrite is not the sole mechanism.

Other possible origin of the faster austenite transformation kinetics is that during faster heating, the nucleation would be shifted to higher temperatures, increasing thereby the driving force and the density of the austenite nuclei. The transformation kinetics would be increased by the higher density of growing fronts of austenite. Such refinement of the microstructure was put into evidence in [23] (considering a hot-rolled initial state, with two heating rates 1 and $\left.300^{\circ} \mathrm{C} . \mathrm{s}^{-1}\right)$. However, in present study, the austenite transformation kinetics is not shifted to much higher temperatures, according to the HEXRD experiments (Figure 5a). The transformation rate of the pearlite islands depends weakly on the heating rate. As for the 
austenite grains forming in the ferrite matrix, their density is not evidently higher at higher heating rate, according to SEM micrographs (compare Figure 6 and Figure 7).

The only effect of the heating rate on the austenite transformation kinetics which is observable on the micrographs concerns the austenite stemming from the pearlite islands. Although the transformation rate of the latter depends weakly on the heating rate (Section 3.4), these transform to coarse, carbon-rich austenite (CRA) grains, which then do show a 732 large difference in growth rate between both heating rates, 3 and $30^{\circ} \mathrm{C} \cdot \mathrm{s}^{-1}$. For example, the CRA grains are clearly larger at $800^{\circ} \mathrm{C}$ after the fast heating (Figure 11). At 760, 770 and $800^{\circ} \mathrm{C}(0 \mathrm{~s})$ the $\mathrm{CRA}$ grains are 3,5 and $10 \mu \mathrm{m}$ thick during slow heating and respectively 10 , 12 and $14 \mu \mathrm{m}$ thick during fast heating. This faster growth could be ascribed in part to the presence of non-recrystallized ferrite, but as mentioned above, this has to be examined with further quantitative microstructural analyses. As the growth of the CRA grains is thermalactivated, there is thus no straightforward interpretation for their faster growth on faster heating. But it explains in part the faster overall kinetics measured by HEXRD (Figure 5). The growth of the CRA grains is further discussed in the modeling part, Section 4.2.3.

746 To conclude, the qualitative analysis of the microstructure evolutions is not sufficient to

747 understand why the austenite transformation is faster during faster heating. The higher final 748 fraction of austenite with faster heating also remains to be interpreted, as well as how this 
749 fraction can exceed the orthoequilibrium (Section 3.3). In the following sections possible

750 outcomes of thermokinetic analyzes are examined.

751

752

753

754

755

756

757

758

759

760

761

762

763

764

765

766

767

768

769

770

771

772

\subsubsection{Thermokinetic analysis}

\subsubsection{Simulation approach; representation of the microstructure}

The austenite transformation is simulated with the DICTRA software [78], which resolves the diffusion equation in a multi-component system. The simulations predict the velocity of the interfaces and the evolutions of the composition profiles. The alloy is simplified here to the ternary Fe-0.1C-1.91Mn (wt.\%) system. As in recent works using DICTRA [30,31,43,44,53], it is assumed that the only rate-limiting process is the diffusion of the alloying elements $\mathrm{Mn}$ and $\mathrm{C}$ and that the local equilibrium holds at the interfaces. (Let us mention that paraequilibrium [1,79] or other deviations to local equilibrium [79-81] have been considered in other studies).

A geometrical representation is defined for both main origins of the austenite: the isolated carbides and the pearlite islands. 1D simulation cells with spherical symmetry, afforded by DICTRA, are utilized (Figure 12). The formation of the austenite stemming from the pearlite islands is simulated in two stages: first, the transformation of the pearlite island to a carbonrich austenite (CRA) grain, then the growth of the latter towards the surrounding ferrite matrix. The simulation cell representing the first stage (Figure 12a) contains a pearlitic spheroidized carbide inside a ferrite matrix; the austenite grows from the exterior. (Hence, it does not describe the transformation of the full pearlite island to a CRA grain, but only one pearlitic carbide). Although this representation is not perfect, it includes an essential feature of the process: the fast diffusion of the alloying elements from the carbide to the austenite, through the ferrite. Next stage is the growth of the CRA grain towards the surrounding ferritic matrix: the geometrical representation by a spherical simulation cell is straightforward (Figure 

12b), although the "true" CRA grains have an elongated shape. The formation of the austenite stemming from the isolated carbides (ANC) is also well represented by a spherical simulation cell (Figure 12c). The austenite is assumed to form rapidly a shell around the carbide. The respective sub-systems or simulation cells will be denoted hereafter P, A and I. (A and P cells serve to describe the formation and then the growth of the of CRA grains; I cell describes the evolution of the ANC).

Figure 12. Spherical simulation cells employed in the DICTRA simulations. a) dissolution of a pearlitic cementite carbide (P sub-system); b) Growth of carbon-rich austenite (CRA) grain into ferrite (A sub-system); c) dissolution of an isolated carbide leading to formation of ANC (I sub-system).

Figure 13 schematizes the representation of the overall microstructure. The starting microstructure consists of pearlite islands and isolated carbides distributed in the ferrite matrix (a). Upon annealing, the austenite will consume the pearlite islands, until the formation of carbon-supersaturated austenite grains (the CRA grains) which will inherit the former pearlite grain size and carbon composition (b). This part of the simulation concerns the cell $\mathrm{P}$. In a second stage, the resulting CRA grains grow into the surrounding ferrite matrix (c), as calculated in the cell A. Meanwhile, austenite transformation from isolated carbides (ANC) is described by the sub-system I. This representation has drastic simplifications: the absence of isolated carbides in the vicinity of the pearlite islands and the fact that there is no transfer of carbon between A and I sub-systems, which are considered as closed systems. Also, the isolated carbides have the same sizes and compositions, contrary to the experimental observations. Consequences of these simplifications will be discussed when comparing the simulations to the experiments. 
Figure 13. Geometrical representation of the microstructure; two stages of austenite transformation. a) Initial microstructure; b) first stage of austenite transformation; c) second stage.

The dimensions inside the simulation cells (Table 2) are based on the measurements by quantitative metallography of the average sizes of the spheroidized pearlitic carbides and the isolated carbides $[49,61]$; the pearlite islands have an average radius of $2.5 \mu \mathrm{m}$, which gives the size of the CRA grain in cell A. The sizes of the carbides are assumed to be the same for both heating rates 30 and $100^{\circ} \mathrm{C} . \mathrm{s}^{-1}$, as no measurements were done for the latter experiment. The total size of cell $\mathrm{P}$ is set by knowing from the experiment the overall carbon concentration in the pearlite islands, 1.78 at. $\%$ and then by applying a molar balance on the carbon. (Carbon concentration in ferrite is close to zero). Setting the total size of cells A and I (i.e. the size of the ferrite "shells") is less straightforward. Indeed, the number density of the isolated carbides and of the CRA grains could not be determined accurately, due to the complexity of the microstructures.

One possible approach could be to set the size of the ferrite shells in cells A and I such that the overall carbon concentration in each cell is the one of the steel, 0.46 at.\%. But it was realized that a respectively higher and lower concentration should be ascribed to cells A and I, to avoid large discrepancies between the simulation and the experiments. Indeed, the carbon distribution is actually heterogeneous. In the initial microstructure, the pearlite islands contain about two thirds of the carbon, but they occupy $16 \%$ of the volume fraction; these high heterogeneities subsist during the intercritical annealing. Different criteria, such as the approximate number density of the isolated carbides, guided the selection of the A and I cell sizes; these criteria are detailed in [61]. As a result, the overall carbon content in cells A and I was set to 0.65 at.\% and 0.30 at.\% respectively. The cell sizes were calculated accordingly by applying carbon molar balances. 
823 The cementite Mn compositions in cells P and I (Table 2) are taken from the EDS measurements detailed in references $[49,61]$. For the heating rate at $100^{\circ} \mathrm{C} . \mathrm{s}^{-1}$, no measurements were done, but it can be expected that the compositions are the same as for the

826 heating at $30^{\circ} \mathrm{C} \cdot \mathrm{s}^{-1}$, because the latter heating rate is already too fast to permit $\mathrm{Mn}$ enrichment

827 in the cementite [61]. In cell A, it is assumed that the CRA grain has the average Mn

828 concentration of the steel $\left(\mathrm{u}^{0} \mathrm{Mn}=1.94 \%\right)$, even though the initial partition of the $\mathrm{Mn}$ inside the cementite platelets could involve local subsisting heterogeneities (so-called ghost cementite).

830 It can be assumed that these heterogeneities are too far from the austenite/ferrite interface to

831 influence its velocity, because of the large dimensions of the cell A. In the ferrite, the Mn

832 content is calculated such that the overall Mn content has the bulk steel composition

$833\left(\mathrm{u}^{0}{ }_{\mathrm{Mn}}=1.94 \%\right)$ in all cells $\mathrm{P}, \mathrm{A}$ and $\mathrm{I}$.

834 Heatings at 3,30 and $100^{\circ} \mathrm{C} \cdot \mathrm{s}^{-1}$ are simulated. The temperature at which the austenite starts to 835 form is taken from the experiments; values are reported in Table 2. DICTRA gives the 836 possibility to trigger the austenite transformation once some critical driving force is overcome 837 (usually $10^{-5}$ RT $[30,82]$ ). However, in view of the limited knowledge regarding the austenite 838 nucleation kinetics, both from present study and literature [76,77,83], setting this critical

839 driving force almost amounts to impose directly the temperature at which the austenite starts 840 to form. For each simulation cell, the same start temperature is used for all heating rates, 841 despite small differences (less than $10^{\circ} \mathrm{C}$ ) according to the experiment. The purpose is to 842 compare more easily the three simulations.

\begin{tabular}{|c|c|c|c|c|}
\hline Heating rate $\left({ }^{\circ} \mathrm{C}^{-1}{ }^{-1}\right)$ & $\theta$ radius $(\mathrm{nm})$ & Total cell radius $(\mathrm{nm})$ & $u^{\theta}{ }_{M n}(\%)$ & Start $\mathbf{T}\left({ }^{\circ} \mathbf{C}\right)$ \\
\hline 3 & 75 & 203 & 8.8 & 720 \\
\hline 30 and 100 & 75 & 203 & 7.2 & 720 \\
\hline Heating rate $\left({ }^{\circ} \mathrm{C} . \mathrm{s}^{-1}\right)$ & $\gamma$ grain radius $(\mathrm{nm})$ & Total cell radius (nm) & $u^{\gamma} M n$ and $u^{\alpha}{ }_{M n}(\%)$ & Start T $\left({ }^{\circ} \mathrm{C}\right)$ \\
\hline
\end{tabular}




\begin{tabular}{|c|c|c|c|c|}
\hline 3,30 and 100 & 2500 & 3530 & 1.94 & 755 \\
\hline Heating rate $\left({ }^{\circ} \mathrm{C} . \mathrm{s}^{-1}\right)$ & $\theta$ radius & Total cell radius (nm) & $u^{\theta} \mathrm{Mn}(\%)$ & Start $\mathbf{T}\left({ }^{\circ} \mathbf{C}\right)$ \\
\hline 3 & 110 & 565 & 8.8 & 720 \\
\hline 30 and 100 & 75 & 373 & 7.2 & 720 \\
\hline
\end{tabular}

Table 2. Main parameters defining the DICTRA simulation cells.

\subsubsection{Results: kinetics related to each sub-system}

847 In the following, the simulation results are presented by focusing on the austenite transformation kinetics. Composition profiles or operative tie-lines are not presented in order to shorten the presentation; these are detailed in [61].

Dissolution of pearlite islands (system P)

851 Figure 14a shows the austenite volume fraction as a function of the temperature during the

852 heating inside the cell $\mathrm{P}$, representing the pearlitic carbide dissolution (Figure 12a, Figure

853 13b). (The cementite fraction is not plotted for clarity). For all heating rates, the

854 transformation kinetics accelerates with increasing temperature because of the faster

855 diffusion. The operative tie-lines and the composition profiles (not presented here) show that

856 the Mn partitions during the transformation. Austenite transformation with partition of $\mathrm{Mn}$ is

857 possible here because of the fast diffusion through the ferrite and the short diffusion distances.

858 The simulation reproduces well the main kinetics features of the pearlite islands

859 transformation, which were established experimentally: the fast kinetics and the weak

860 dependence on the heating rate. Indeed, the curves are shifted only by $10^{\circ} \mathrm{C}$ between $3^{\circ} \mathrm{C} \cdot \mathrm{s}^{-1}$

861 and $100^{\circ} \mathrm{C} \cdot \mathrm{s}^{-1}$ heating rates. The temperature range for the transformation of the pearlite

862 islands is also in agreement with the microstructure observations (at 3 and $30^{\circ} \mathrm{C} \cdot \mathrm{s}^{-1}$ ). 
864

865

866

867

868

869

870

871

872

873

874

875

876

877

878

879

880

881

882

883

884

885

886

887

Figure 14. Austenite volume fraction as a function of temperature according to DICTRA simulations inside the simulation cells represented in Figure 12a-b. a) transformation of the pearlite island (sub-system P); b) growth of the CRA grain (sub-system A). OE and NPLE curves represent the austenite volume fraction at equilibrium and after a ferrite to austenite transformation without partition of the $\mathrm{Mn}$; c) carbon concentration profiles at $780^{\circ} \mathrm{C}$ in simulation cell $\mathrm{A}$, as a function of the distance from the center of the simulation cell.

\section{Growth of the CRA grains (system A)}

Next stage is the growth of the CRA grain towards the surrounding ferritic matrix. The evolution of the austenite fraction inside the A simulation cell (Figure 12b, Figure 13c) is plotted in Figure 14b for all heating rates. This time, the austenite transformation occurs without partition of the $\mathrm{Mn}$ in all cases. (Tie-lines and Mn concentration profiles are again not presented). All simulation curves tend to follow one single curve denoted NPLE (calculated with Thermocalc), which corresponds to the maximum fraction of austenite which can be formed without Mn partition. There is an apparent discrepancy for both highest heating rates (30 and $100^{\circ} \mathrm{C} \cdot \mathrm{s}^{-1}$ ), but it corresponds to a time discrepancy of less than $1 \mathrm{~s}$. In fact, for heating rates $30^{\circ} \mathrm{C} \cdot \mathrm{s}^{-1}$ and $100^{\circ} \mathrm{C} \cdot \mathrm{s}^{-1}$, the carbon has not enough time to diffuse and to reach a homogeneous concentration inside the austenite. This is illustrated in Figure 14c which shows the carbon concentration profiles calculated for instance at $780^{\circ} \mathrm{C}$. However, the operative tieline at the $\gamma / \alpha$ interface is the same one for the three heating rates; it corresponds to the NPLE regime. This is illustrated by the carbon concentration in the austenite at the $\gamma / \alpha$ interface, which is the same for the three heating rates. Due to the high carbon concentration ascribed to the cell A (see previous Section), full austenite transformation is achieved at $800^{\circ} \mathrm{C}$ at $3{ }^{\circ} \mathrm{C} \cdot \mathrm{s}^{-1}$, and in less than $2 \mathrm{~s}$ at $800^{\circ} \mathrm{C}$ after both heatings at 30 and $100^{\circ} \mathrm{C} \cdot \mathrm{s}^{-1}$.

\section{Dissolution of isolated carbide and growth of ANC (system I)}


888 Figure 15a shows the result of the simulation for the austenite stemming from the isolated carbides during the heating up to $800^{\circ} \mathrm{C}$. For all heating rates, three stages can be identified.

890 The first slow stage corresponds to the carbide dissolution involving the partition of the Mn.

891 The sharp acceleration at the second stage corresponds to the shift to a regime of dissolution

892 without partition (PLE $\rightarrow$ NPLE). It occurs at the partition-no partition transition temperature

893 (PNTT [45]), which can be calculated from thermodynamic data, as presented in

$894[42,43,45,46]$. The PNTT increases with increasing Mn concentration in cementite. The

895 PNTTs calculated with Thermocalc are equal to $730^{\circ} \mathrm{C}$ at $3^{\circ} \mathrm{C} \cdot \mathrm{s}^{-1}$ and $725^{\circ} \mathrm{C}$ at 30 and

$896100^{\circ} \mathrm{C} \cdot \mathrm{s}^{-1}$. These values are in agreement with the DICTRA simulations. The last stage

897 corresponds to the final ferrite/austenite transformation. Like for the CRA grains growth, it

898 occurs without Mn partition and the austenite fraction follows again the maximum predicted 899 for this regime (NPLE curve). The discrepancy at $3^{\circ} \mathrm{C} \cdot \mathrm{s}^{-1}$ comes from the fact that significant 900 partition of Mn occurred during the first stage.

Figure 15. Austenite volume fraction evolution according to DICTRA simulations representative of the isolated carbides dissolution (sub-system I). a) during heating, as a function of temperature; b) during isothermal hold at $800^{\circ} \mathrm{C}$. OE and NPLE curves have the same meaning as in Figure 14. (Values are different because of the different overall carbon concentration in cells A and I, see Table 2).

906 The ferrite to austenite transformation goes on during the isothermal hold at $800^{\circ} \mathrm{C}$ after all 907 heating rates (Figure 15b). In this stage, the Mn partitions from the ferrite to the austenite and 908 the kinetics is controlled by the diffusion of the Mn inside the ferrite [61]. After the heating at $90933^{\circ} \mathrm{C} \cdot \mathrm{s}^{-1}$, the austenite fraction slightly overcomes the equilibrium value in less than $10 \mathrm{~s}$, in 910 accordance with the experiment, if taking account of the experimental uncertainties. Actually, 911 the system is not fully equilibrated, as heterogeneities in Mn concentration subsist in the 912 austenite [61]. After the heating at $30^{\circ} \mathrm{C} \cdot \mathrm{s}^{-1}$, the austenite fraction also reaches a plateau in 
913 less than $10 \mathrm{~s}$, but the final fraction exceeds the OE value by ca. 10\%. The discrepancy is

914 even higher at $100^{\circ} \mathrm{C} \cdot \mathrm{s}^{-1}$. This "overshoot" of the austenite OE fraction comes from the

915 absence of $\mathrm{Mn}$ partition up to $800^{\circ} \mathrm{C}$. As a result, there is more $\mathrm{Mn}$ remaining available to

916 partition from the ferrite to the austenite, and more austenite will thus be formed. Similar

917 conclusion was reached in [30]. A final stage towards the equilibration is observable for both

918 faster heatings: after ca. $100 \mathrm{~s}$, the austenite fraction decreases slowly; the kinetics is then

919 controlled by the Mn diffusion in the austenite, which is about 100 times slower than in the

920 ferrite.

921 The previous kinetics simulations allow to understand why the austenite transformation

922 kinetics is faster during faster heating. One common result comes out: after the dissolution of

923 the cementite carbides (either isolated in the matrix or inside pearlite islands), the further

924 ferrite/austenite transformation always occurs without partition of Mn during the heating up to

$925800^{\circ} \mathrm{C}$ (for the investigated range of heating rates). As a result, the transformation kinetics

926 depends only on the temperature, because the austenite fraction follows in each sub-system

927 some maximum fraction (denoted NPLE in the curves), which is predictable from

928 thermodynamics. Consequently, faster heating leads to faster austenite transformation

929 kinetics. Accordingly, the experimental curves in Figure 5 do show kinetics which depend

930 only on the temperature, with small differences between heating rates $3^{\circ} \mathrm{C} \cdot \mathrm{s}^{-1}, 30^{\circ} \mathrm{C} \cdot \mathrm{s}^{-1}$ and

$931100^{\circ} \mathrm{C} . \mathrm{s}^{-1}$. Some microstructural observations are in good agreement with these simulations.

932 As presented in Section 4.2.2, the CRA grains grow faster during faster heating, according to

933 the measurements. Direct experimental confirmation is nevertheless more difficult for the

934 austenite stemming from the isolated carbides, as the kinetics specific to each carbide are

935 more scattered. Finally, the "overshoot" of the equilibrium austenite fraction during

936 isothermal hold after the fast heating comes from the absence of Mn redistribution during

937 heating after the carbides dissolution, as presented above. 


\subsubsection{Results: overall kinetics during the heating stage}

939

940

941 pearlite islands and the isolated carbides.

$942 f^{\gamma}=f_{P}^{\gamma} f_{P}+f_{I}^{\gamma} f_{I}$

943 where $f_{P}^{\gamma}$ and $f_{I}^{\gamma}$ are the volume fractions of austenite calculated in the sub-systems P and I

944 (the results are plotted in Figure 14a and Figure 15). $f_{P}$ is the volume fraction of the pearlite

945 islands, which is known experimentally: $f_{P}=16 \%$ (Section 3.1.1). $f_{I}$ is the volume fraction ascribed to the isolated carbide sub-system; it is calculated hereafter.

Second stage corresponds to the growth of the CRA grains into the surrounding ferrite matrix, while the austenite transformation from the isolated carbides continues.

$$
f^{\gamma}=f_{A}^{\gamma} f_{A}+f_{I}^{\gamma} f_{I}
$$

where $f_{A}^{\gamma}$ is the volume fraction of austenite calculated in the sub-system A (results are plotted in Figure $14 \mathrm{~b}$ ) and $f_{A}$ the volume fraction occupied by the sub-system $\mathrm{A}$.

Assuming for simplicity that the volume and the molar fractions are equal, the carbon is distributed in A and I sub-systems according to the following molar balances:

$r x_{C}^{0}=f_{A} x_{C}^{A}$

and

$$
(1-r) x_{C}^{0}=f_{I} x_{C}^{I}
$$

where $x_{C}^{0}$ is the molar carbon content of the steel, 0.453 at.\%, $x_{C}^{A}$ and $x_{C}^{I}$ are the carbon molar concentrations in sub-systems A and I. $r$ is the proportion of the carbon of the steel inside the A sub-system. It is equal to the proportion of carbon inside the pearlite islands in the initial 
960

961

962

963

964

965

966

967

968

969

970

971

972

973

974

975

976

978

979

microstructure, because the CRA grains inherit the carbon of their parent pearlite island. $r$ is known from the experiments (Section 3.1.1): $\mathrm{r}=64 \%$. The proportion of carbon inside the isolated carbides is equal to $(1-r)$. Both previous equations let one degree of freedom to

calculate $f_{A}, f_{I}, x_{C}^{A}$ and $x_{C}^{I}$ (knowing that $f_{A}+f_{I}=1$ ). As mentioned above, $x_{C}^{A}$ and $x_{C}^{I}$ were set to $x_{C}^{A}=0.65$ at. $\%$ and $x_{C}^{I}=0.30$ at. $\%$ by following an approach detailed in [61]. From previous equations, $f_{A}=44 \%$ and $f_{I}=56 \%$.

Figure 16 shows the calculated overall austenite fraction during the heating as a function of the temperature for the three heating rates 3,30 and $100^{\circ} \mathrm{C} \cdot \mathrm{s}^{-1}$. Four stages are visible: (i) sluggish cementite dissolution in I sub-system (isolated carbides); (ii) sharp acceleration when the PNTT is reached in I sub-system; (iii) pearlite islands transformation (P sub-system); (iv) ferrite to austenite transformation without Mn partition (NPLE regime) in both $\mathrm{A}^{1}$ and I subsystems. The curve denoted NPLE represents the sum of the NPLE austenite fractions inside I and A subsystems $\left(f^{N P L E}=f_{A}^{N P L E} f_{A}+f_{I}^{N P L E} f_{I}\right)$.

Figure 16. Overall austenite fraction as a function of temperature during heating at 3,30 and $100^{\circ} \mathrm{C}^{-1}$ according the simulation (lines) and the experiments (dots). Main stages are indicated by the arrows.

\footnotetext{
${ }^{1}$ The simulations in cell A are started at 749,755 and $766^{\circ} \mathrm{C}$ at 3,30 and $100^{\circ} \mathrm{C} \cdot \mathrm{s}^{-1}$ respectively, unlike the simulations presented previously (Section 4.2.2), which were started at $755^{\circ} \mathrm{C}$. The three temperatures correspond to the end of the austenite transformation in cell $\mathrm{P}$ for the three heating rates.
} 
980 particularly true above ca. $760^{\circ} \mathrm{C}$, during the final ferrite to austenite transformation under

981 NPLE regime: the three simulations are close to the "NPLE curve". Hence, despite the

982 discrepancies with the experiments, these simulations show that the similar kinetics for the

983 three heating rates can reasonably be explained by the partitionless growth of the austenite

984 during the heating, once the cementite has fully dissolved. Other possible origins of the faster

985 kinetics, such as the more intense nucleation or the presence of non-recrystallized ferrite (see

986 Section 4.2.2) should still be investigated with more quantitative microstructural

987 characterizations. However, the kinetic analysis presented here is likely to remain valid

988 whatever these further improvements. It already explains in large part the kinetic trends

989 during the heating.

990 Although the simulation framework introduced here allowed to interpret the influence of the

991 heating rate on the austenite transformation kinetics, it is not yet sufficiently precise for

992 quantitative predictions. As can be seen in Figure 16, the overall kinetics is largely

993 overestimated (except at $\left.100^{\circ} \mathrm{C} . \mathrm{s}^{-1}\right)$. There are several origins:

994 - The simplification to the ternary Fe-C-Mn system (instead of Fe-C-Mn-Cr-Si) which

995 makes overestimate the austenite fraction by about 5\%. The $\mathrm{Cr}$ also strongly stabilizes the

996 cementite by increasing the PNTT [42], even when it is a minor element of the steel,

997 according to kinetic simulations [48].

998 - Considering for the isolated carbides distributions of size and $\mathrm{Mn} / \mathrm{Cr}$ composition would

999 spread their dissolution in a larger temperature range and thus slow down the calculated

1000 overall kinetics. Progressive nucleation of the austenite should also be considered, as

1001 shown by the microstructural observations. This is thought to be the main origin of the too

1002 sharp and early start of the simulations at 30 and $100^{\circ} \mathrm{C} . \mathrm{s}^{-1}$, compared to the experiment.

1003 - The geometry of the I cell is actually no more representative once the austenite has

1004 decorated the ferrite grain boundaries to form the necklace network (see e.g. Figure 7). 
The austenite then grows to the ferrite from the exterior, instead of the center of the simulation cell, as assumed currently. This low representativeness of the I simulation cell at late stages is the reason why the simulations are not compared to the experiment during the isothermal hold step. Nevertheless, the current geometrical representation already allows to predict the "overshoot" of austenite fraction above the OE value after faster heating.

1011 Final possible improvement concerns the distribution of the carbon between the austenite stemming respectively from the isolated carbides and from the pearlite islands. A carbon concentration of 0.65 at. $\%$ and 0.30 at.\% was ascribed respectively to the A and I simulation cells (Section 4.2.3.1), in order to reflect the carbon concentration heterogeneity coming from

1015 the initial microstructure. However, there is probably a transfer of the carbon from the A sub1016 system to the I sub-system during the heating. As seen in Figure 6 and Figure 7, the austenite grains stemming from the pearlite islands and the isolated carbides end up to percolate and to

1018 form one single network of austenite, inside which the carbon concentration will tend to 1019 homogenize. The hypothesis of closed A and I subsystems is probably too strict.

1020 This may explain another discrepancy that we have not yet pointed out, concerning the size of 1021 the CRA grains. According to the current simulations in A cell, the CRA grains should reach 1022 for the three heating rates nearly the same size at $800^{\circ} \mathrm{C}$. Indeed, the austenite fraction is 1023 nearly the same (with time shifts less than $2 \mathrm{~s}$ ), as shown in Figure 14a. However, the 1024 observation (Figure 11) shows that the CRA grains are clearly larger after the heating at $102530^{\circ} \mathrm{C} . \mathrm{s}^{-1}$ than at $3^{\circ} \mathrm{C} . \mathrm{s}^{-1}$. It is thought that during the slow heating, the carbon has more time to 1026 leave the CRA grains towards the austenite necklace network. The CRA grains would thus 1027 reach a smaller size, because the carbon concentration in austenite remains fixed by the 1028 equilibrium tie-line corresponding to the NPLE growth regime. Actually, this transfer of 1029 carbon from the pearlite bands to the austenite network at grain boundaries may be another 
1030 origin of the transition from the banded to the necklace microstructure when decreasing the

1031 heating rate.

1032 Final comment regards the influence of the non-recrystallized ferrite on the austenite

1033 transformation kinetics. The defects present in the ferrite would accelerate the diffusion

1034 according to previous works [2,24,29]. According to our simulations, this is not thought to

1035 have significant consequences during the heating stage. Indeed, the austenite grows under the

1036 NPLE regime and therefore, the rate-limiting process is the diffusion of carbon inside the

1037 austenite. (As was already pointed out in reference [1], see the Figure 10). This is illustrated

1038 by the examples of carbon concentration profiles plotted in Figure 14c inside the simulation

1039 cell A. The carbon concentration in austenite has not enough time to homogenize, while it

1040 remains close to zero and homogeneous inside the ferrite. Hence, accelerating or not the

1041 diffusion inside the ferrite would not change the simulation results. During the subsequent

1042 isothermal step at $800^{\circ} \mathrm{C}$, the rate-limiting process is then the Mn diffusion inside the ferrite,

1043 according to the simulations in cell I. But at this temperature, the ferrite is fully or almost

1044 fully recrystallized, according to our experiments (Section 3.2).

1045

1046

1047 


\section{Conclusion}

1049 The austenite transformation occurring during the intercritical annealing of a dual-phase Fe-

$1050 \quad 0.1 \mathrm{C}-1.9 \mathrm{Mn}-0.2 \mathrm{Cr}-0.2 \mathrm{Si}$ wt.\% (DP-600) steel has been investigated. The initial

1051 microstructure is ferrite-pearlite cold-rolled to $60 \%$ amount of reduction. Three heating rates

1052 have been applied, slow $\left(3^{\circ} \mathrm{C} . \mathrm{s}^{-1}\right)$ and fast $\left(30\right.$ or $\left.100^{\circ} \mathrm{C} \cdot \mathrm{s}^{-1}\right)$ before an isothermal holding at

$1053800^{\circ} \mathrm{C}$, to induce weak or strong interactions between the austenite transformation, the ferrite

1054 recrystallization and the cementite carbides ripening. Main conclusions are the following:

1055 - The initial microstructure contains a large number of intergranular and isolated cementite

1056 carbides inherited form the hot-rolling stage and distributed outside the pearlite islands.

1057 These carbides contain about one third of the carbon of the steel. The pearlitic cementite

1058 contains the remainder of the carbon.

1059 - These isolated carbides play a predominant role in the austenite morphogenesis. A

1060 necklace or a banded austenite microstructure is generated respectively on slow and fast

1061 heating, depending on whether or not the ferrite recrystallization has enough time to

1062 modify their spatial distribution with respect to the ferrite grain boundaries, and thus the

1063 nucleation sites and the carbon sources for the austenite. Our experimental results sustain

1064 the analysis proposed by Li et al. [26].

1065 - The austenite transformation starts with a slow kinetic regime corresponding to the

1066 cementite dissolution involving the partition of the substitutional elements.

1067 - Two sub-systems with different kinetic behavior are then identified. The pearlite islands

1068 transform simultaneously to austenite in a narrow temperature range which depends

1069 weakly on the heating rate. The process still involves the partition of the substitutional

1070 elements, but is accelerated because of the low diffusion distances inside the pearlitic

1071 ferrite. In contrast, the austenite nucleates and grows more progressively from the isolated

1072 carbides. The latter dissolve quickly, without partition, once some critical partition-non 
1073 partition transition temperature (PNTT) has been reached. The PNTT is predictable from

1074 thermodynamic data; it increases with increasing Mn concentration in cementite carbides.

1075 - During heating up to $800^{\circ} \mathrm{C}$, the final stage corresponds to a ferrite to austenite

1076 transformation, without partition of the substitutional elements. During the isothermal

1077 holding at $800^{\circ} \mathrm{C}$, the austenite transformation continues with partition. The rate-limiting

1078 process is the diffusion of substitutional elements in the ferrite and finally in the austenite.

1079 - The faster transformation during faster heating is largely explained by the partitionless

1080 austenite transformation during this last stage, as shown by DICTRA simulations. The

1081 austenite fraction stays close to a maximum value which only depends on the temperature

1082 and which is predictable from thermodynamics (NPLE fraction). However, other possible

1083 origins such as the presence of non-recrystallized ferrite or faster nucleation should still be

$1084 \quad$ considered.

1085 - DICTRA simulations of austenite transformation achieve to predict kinetics orders of

1086 magnitude during the heating stage and the influence of the heating rate. However, the

1087 geometrical representation of the microstructure has to be improved for accurate

1088 predictions and to encompass both the heating and the holding stages in the simulations.

1089

\section{Acknowledgements}

1091 This research was funded by the Centre National de la Recherche Scientifique (CNRS) and by 1092 ArcelorMittal Maizières-lès-Metz (Product Research Centre). The Laboratory of Excellence 1093 on Design of Alloy Metals for low-mAss Structures (Labex DAMAS belongs to the program

1094 "Investment in the future" operated by the National Research Agency (ANR) and referenced 1095 by ANR-11-LABX-0008-01) from Université de Lorraine (France) is also fully 1096 acknowledged for its support. Dr M. Salib and Mr G. Petitgand (at ArcelorMittal) are 
1097 acknowledged for the EBSD observation and the WDS analyses. Dr J. Ghanbaja (IJL) is

1098 acknowledged for the TEM observations and EDS analyses.

1099

\section{Bibliography}

1101 [1] G.R. Speich, V.A. Demarest, R.L. Miller, Formation of Austenite During Intercritical

1102 Annealing of Dual-Phase Steels, Metall. Mater. Trans. A. 12 (1981) 1419-1428.

1103 https://doi.org/10.1007/BF02643686.

1104 [2] M. Kulakov, W.J. Poole, M. Militzer, The Effect of the Initial Microstructure on

1105 Recrystallization and Austenite Formation in a DP600 Steel, Metall. Mater. Trans. A. 44

1106 (2013) 3564-3576. https://doi.org/10.1007/s11661-013-1721-z.

1107 [3] T. Allam, M. Abbas, Mechanical Properties, Formability, and Corrosion Behavior of

1108 Dual Phase Weathering Steels Developed by an Inter-Critical Annealing Treatment, Steel

1109 Res. Int. 86 (2015) 231-240. https://doi.org/10.1002/srin.201400033.

1110 [4] H. Hofmann, D. Mattissen, T.W. Schaumann, Advanced cold rolled steels for

1111 automotive applications, Mater. Werkst. 37 (2006) 716-723.

1112 https://doi.org/10.1002/mawe.200600057.

1113 [5] E. De Moor, D.K. Matlock, J.G. Speer, M.J. Merwin, Austenite stabilization through

1114 manganese enrichment, Scr. Mater. 64 (2011) 185-188.

1115 https://doi.org/10.1016/j.scriptamat.2010.09.040.

1116 [6] P. Movahed, S. Kolahgar, S.P.H. Marashi, M. Pouranvari, N. Parvin, The effect of

1117 intercritical heat treatment temperature on the tensile properties and work hardening behavior

1118 of ferrite-martensite dual phase steel sheets, Mater. Sci. Eng. A. 518 (2009) 1-6.

1119 https://doi.org/10.1016/j.msea.2009.05.046. 
1121 First Family of Advanced High Strength Steels, in: Ref. Module Mater. Sci. Mater. Eng.,

1122 Elsevier, 2020. https://doi.org/10.1016/B978-0-12-819726-4.00057-0.

1123 [8] N. Fonstein, Advanced High Strength Sheet Steels Physical Metallurgy, Design,

1124 Processing, and Properties, Springer, Cham, n.d. https://doi.org/10.1007/978-3-319-19165-2.

1125 [9] M. Erdogan, Effect of austenite dispersion on phase transformation in dual phase steel, 1126 Scr. Mater. 48 (2003) 501-506. https://doi.org/10.1016/S1359-6462(02)00500-6.

1127 [10] P. Jacques, F. Delannay, X. Cornet, Ph. Harlet, J. Ladriere, Enhancement of the 1128 mechanical properties of a low-carbon, low-silicon steel by formation of a multiphased

1129 microstructure containing retained Austenite, Metall. Mater. Trans. A. 29 (1998) 2383-2393.

1130 https://doi.org/10.1007/s11661-998-0114-1.

1131 [11] S.Y.P. Allain, O. Bouaziz, I. Pushkareva, C.P. Scott, Towards the microstructure 1132 design of DP steels: A generic size-sensitive mean-field mechanical model, Mater. Sci. Eng. 1133 A. 637 (2015) 222-234. https://doi.org/10.1016/j.msea.2015.04.017.

1134 [12] C.C. Tasan, J.P.M.M. Hoefnagels, M. Diehl, D. Yan, F. Roters, D. Raabe, Strain 1135 localization and damage in dual phase steels investigated by coupled in-situ deformation 1136 experiments and crystal plasticity simulations, Int. J. Plast. 63 (2014) 198-210.

1137 https://doi.org/10.1016/j.ijplas.2014.06.004.

1138 [13] G. Avramovic-Cingara, Y. Ososkov, M.K. Jain, D.S. Wilkinson, Effect of martensite 1139 distribution on damage behaviour in $\{$ DP600 $\}$ dual phase steels, Mater. Sci. Eng. A. 516 1140 (2009) 7-16. https://doi.org/10.1016/j.msea.2009.03.055.

1141 [14] V. Uthaisangsuk, S. Muenstermann, U. Prahl, W. Bleck, H.-P. Schmitz, T. Pretorius, 1142 A study of microcrack formation in multiphase steel using representative volume element and 1143 damage mechanics, Comput. Mater. Sci. 50 (2011) 1225-1232. 
1144 https://doi.org/10.1016/j.commatsci.2010.08.007.

1145 [15] K. Ismail, A. Perlade, P.J. Jacques, T. Pardoen, L. Brassart, Impact of second phase

1146 morphology and orientation on the plastic behavior of dual-phase steels, Int. J. Plast. 118

1147 (2019) 130-146. https://doi.org/10.1016/j.ijplas.2019.02.005.

1148 [16] S.D. Martín, de T. Cock, A. García-Junceda, F.G. Caballero, C. Capdevila, C.G. de

1149 Andrés, Effect of heating rate on reaustenitisation of low carbon niobium microalloyed steel,

1150 Mater. Sci. Technol. 24 (2008) 266-272. https://doi.org/10.1179/174328408X265640.

1151 [17] J. Agren, H. Abe, T. Suzuki, Y. Sakuma, The dissolution of cementite in a low carbon

1152 steel during isothermal annealing at $700^{\circ} \mathrm{C}$, Metall. Trans. A. 17 (1986) 617-620.

1153 https://doi.org/10.1007/BF02643980.

1154 [18] A. Arlazarov, M. Gouné, O. Bouaziz, A. Hazotte, G. Petitgand, P. Barges, Evolution

1155 of microstructure and mechanical properties of medium Mn steels during double annealing,

1156 Mater. Sci. Eng. A. 542 (2012) 31-39. https://doi.org/10.1016/j.msea.2012.02.024.

1157 [19] M. Mazinani, W.J. Poole, Effect of Martensite Plasticity on the Deformation Behavior

1158 of a Low-Carbon Dual-Phase Steel, Metall. Mater. Trans. A. 38 (2007) 328-339.

1159 https://doi.org/10.1007/s11661-006-9023-3.

1160 [20] G. Avramovic-Cingara, Y. Ososkov, M.K. Jain, D.S. Wilkinson, Effect of martensite

1161 distribution on damage behaviour in DP600 dual phase steels, Mater. Sci. Eng. A. 516 (2009)

1162 7-16. https://doi.org/10.1016/j.msea.2009.03.055.

1163 [21] C.C. Tasan, J.P.M. Hoefnagels, M. Diehl, D. Yan, F. Roters, D. Raabe, Strain

1164 localization and damage in dual phase steels investigated by coupled in-situ deformation

1165 experiments and crystal plasticity simulations, Int. J. Plast. 63 (2014) 198-210.

1166 https://doi.org/10.1016/j.ijplas.2014.06.004.

1167 [22] V. Andrade-Carozzo, P.J. Jacques, Interactions between Recrystallisation and Phase 
1168 Transformations during Annealing of Cold Rolled Nb-Added TRIP-Aided Steels, Mater. Sci.

1169 Forum. 539-543 (2007) 4649-4654. https://doi.org/10.4028/www.scientific.net/MSF.539-

$1170 \quad 543.4649$.

1171 [23] H. Azizi-Alizamini, M. Militzer, W.J. Poole, Austenite Formation in Plain Low-

1172 Carbon Steels, Metall. Mater. Trans. A. 42 (2011) 1544-1557.

1173 https://doi.org/10.1007/s11661-010-0551-5.

1174 [24] A. Chbihi, D. Barbier, L. Germain, A. Hazotte, M. Gouné, Interactions between ferrite

1175 recrystallization and austenite formation in high-strength steels, J. Mater. Sci. 49 (2014)

1176 3608-3621. https://doi.org/10.1007/s10853-014-8029-2.

1177 [25] J. Huang, W.J. Poole, M. Militzer, Austenite formation during intercritical annealing,

1178 Metall. Mater. Trans. A. 35 (2004) 3363-3375. https://doi.org/10.1007/s11661-004-0173-x.

1179 [26] P. Li, J. Li, Q. Meng, W. Hu, D. Xu, Effect of heating rate on ferrite recrystallization

1180 and austenite formation of cold-roll dual phase steel, J. Alloys Compd. 578 (2013) 320-327.

1181 https://doi.org/10.1016/j.jallcom.2013.05.226.

1182 [27] L.S. Thomas, D.K. Matlock, Formation of Banded Microstructures with Rapid

1183 Intercritical Annealing of Cold-Rolled Sheet Steel, Metall. Mater. Trans. A. 49 (2018) 4456-

1184 4473. https://doi.org/10.1007/s11661-018-4742-9.

1185 [28] R.R. Mohanty, O.A. Girina, N.M. Fonstein, Effect of Heating Rate on the Austenite

1186 Formation in Low-Carbon High-Strength Steels Annealed in the Intercritical Region, Metall.

1187 Mater. Trans. A. 42 (2011) 3680-3690. https://doi.org/10.1007/s11661-011-0753-5.

1188 [29] D. Barbier, L. Germain, A. Hazotte, M. Gouné, A. Chbihi, Microstructures resulting

1189 from the interaction between ferrite recrystallization and austenite formation in dual-phase

1190 steels, J. Mater. Sci. 50 (2015) 374-381. https://doi.org/10.1007/s10853-014-8596-2.

1191 [30] Q. Lai, M. Gouné, A. Perlade, T. Pardoen, P. Jacques, O. Bouaziz, Y. Bréchet, 
1192 Mechanism of Austenite Formation from Spheroidized Microstructure in an Intermediate Fe-

1193 0.1C-3.5Mn Steel, Metall. Mater. Trans. A. 47 (2016) 3375-3386.

1194 https://doi.org/10.1007/s11661-016-3547-y.

1195 [31] R. Wei, M. Enomoto, R. Hadian, H.S. Zurob, G.R. Purdy, Growth of austenite from 1196 as-quenched martensite during intercritical annealing in an Fe-0.1C-3Mn-1.5Si alloy, Acta 1197 Mater. (2013) 11.

1198 [32] C.I. Garcia, A.J. Deardo, Formation of austenite in 1.5 pct Mn steels, Metall. Trans. A. 119912 (1981) 521-530. https://doi.org/10.1007/BF02648551.

1200 [33] D.Z. Yang, E.L. Brown, D.K. Matlock, G. Krauss, Ferrite recrystallization and 1201 austenite formation in cold-rolled intercritically annealed steel, Metall. Trans. A. 16 (1985) 1202 1385-1392. https://doi.org/10.1007/BF02658671.

1203 [34] S. Chattopadhyay, C.M. Sellars, Quantitative measurements of pearlite 1204 spheroidization, Metallography. 10 (1977) 89-105. https://doi.org/10.1016/00261205 0800(77)90044-1.

1206 [35] S. Chattopadhyay, C.M. Sellars, Kinetics of pearlite spheroidisation during static 1207 annealing and during hot deformation, Acta Metall. 30 (1982) 157-170.

1208 https://doi.org/10.1016/0001-6160(82)90055-4.

1209 [36] M. Etou, S. Fukushima, T. Sasaki, Y. Haraguchi, K. Miyata, M. Wakita, T. Tomida, 1210 N. Imai, M. Yoshida, Y. Okada, Super Short Interval Multi-pass Rolling Process for 1211 Ultrafine-grained Hot Strip, ISIJ Int. 48 (2008) 1142-1147.

1212 https://doi.org/10.2355/isijinternational.48.1142.

1213 [37] Y. Yin, J. Sun, A. Zhao, J. Gou, Ultra-low-carbon steel spheroidization and torsion, J. 1214 Iron Steel Res. Int. 25 (2018) 968-974. https://doi.org/10.1007/s42243-018-0137-9.

1215 [38] T.H. Courtney, J.C.M. Kampe, Shape instabilities of plate-like structures-II. 
1216 Analysis, Acta Metall. 37 (1989) 1747-1758. https://doi.org/10.1016/0001-6160(89)90060-6.

1217 [39] J. Arruabarrena, B. López, J.M. Rodriguez-Ibabe, Influence of Prior Warm

1218 Deformation on Cementite Spheroidization Process in a Low-Alloy Medium Carbon Steel,

1219 Metall. Mater. Trans. A. 45 (2014) 1470-1484. https://doi.org/10.1007/s11661-013-2066-3.

1220 [40] J.J. Yi, I.S. Kim, H.S. Choi, Austenitization during intercritical annealing of an Fe-C-

1221 Si-Mn dual-phase steel, Metall. Trans. A. 16 (1985) 1237-1245.

1222 https://doi.org/10.1007/BF02670328.

1223 [41] Z.-K. Liu, L. Höglund, B. Jönsson, J. ågren, An experimental and theoretical study of

1224 cementite dissolution in an Fe-Cr-C alloy, Metall. Trans. A. 22 (1991) 1745-1752.

1225 https://doi.org/10.1007/BF02646498.

1226 [42] G. Miyamoto, H. Usuki, Effects of Mn, Si and Cr addition on reverse transformation

1227 at 1073K from spheroidized cementite structure in Fe-0.6 mass\% C alloy, Acta Mater. (2010)

122811.

1229 [43] M. Gouné, P. Maugis, J. Drillet, A Criterion for the Change from Fast to Slow Regime

1230 of Cementite Dissolution in Fe-C-Mn Steels, J. Mater. Sci. Technol. 28 (2012) 728-736.

1231 https://doi.org/10.1016/S1005-0302(12)60122-4.

1232 [44] Y. Xia, M. Enomoto, Z. Yang, Z. Li, C. Zhang, Effects of alloying elements on the

1233 kinetics of austenitization from pearlite in Fe-C-M alloys, Philos. Mag. 93 (2013) 1095-

1234 1109. https://doi.org/10.1080/14786435.2012.744484.

1235 [45] M. Enomoto, S. Li, Z.N. Yang, C. Zhang, Z.G. Yang, Partition and non-partition

1236 transition of austenite growth from a ferrite and cementite mixture in hypo- and

1237 hypereutectoid Fe-C-Mn alloys, Calphad. 61 (2018) 116-125.

1238 https://doi.org/10.1016/j.calphad.2018.03.002.

1239 [46] M. HILLERT, K. NILSSON, L. TORNDAHL, EFFECT OF ALLOYING 
1241 J. Iron Steel Inst. 209 (1971) 49-.

1242 [47] Y.X. Wu, L.Y. Wang, W.W. Sun, M.J. Styles, A.J. Studer, Y. Bréchet, A. Arlazarov,

1243 C.R. Hutchinson, Austenite formation kinetics from multicomponent cementite-ferrite

1244 aggregates, Acta Mater. 196 (2020) 470-487. https://doi.org/10.1016/j.actamat.2020.07.001.

1245 [48] A. Marceaux dit Clément, K. Hoummada, J. Drillet, V. Hébert, P. Maugis, Effects of 1246 cementite size and chemistry on the kinetics of austenite formation during heating of a high-

1247 formability steel, Comput. Mater. Sci. 182 (2020) 109786.

1248 https://doi.org/10.1016/j.commatsci.2020.109786.

1249 [49] M. Moreno, J. Teixeira, J. Ghanbaja, F. Bonnet, S. Allain, Evolution of cementite 1250 composition along the processing of cold-rolled and annealed Dual-Phase steels, Materialia. 6 1251 (2019) 100179. https://doi.org/10.1016/j.mtla.2018.100179.

1252 [50] R. Petrov, L. Kestens, Y. Houbaert, Recrystallization of a Cold Rolled Trip-assisted

1253 Steel during Reheating for Intercritical Annealling., ISIJ Int. 41 (2001) 883-890.

1254 https://doi.org/10.2355/isijinternational.41.883.

1255 [51] N. Maruyama, T. Ogawa, M. Takahashi, Recrystallisation at Intercritical Annealing in 1256 Low Carbon Steels, Mater. Sci. Forum. (2007).

1257 https://doi.org/10.4028/www.scientific.net/MSF.558-559.247.

1258 [52] S. Dillien, M. Seefeldt, S. Allain, O. Bouaziz, P. Van Houtte, EBSD study of the 1259 substructure development with cold deformation of dual phase steel, Mater. Sci. Eng. A. 527 1260 (2010) 947-953. https://doi.org/10.1016/j.msea.2009.09.009.

1261 [53] M. Ollat, Characterization and modeling of microstructural evolutions during the

1262 thermal treatment of cold-rolled Dual-Phase steels, phdthesis, Université de Lyon, 2017. 1263 https://tel.archives-ouvertes.fr/tel-01920855 (accessed January 30, 2020). 
1264 [54] T. Ogawa, N. Maruyama, N. Sugiura, N. Yoshinaga, Incomplete Recrystallization and

1265 Subsequent Microstructural Evolution during Intercritical Annealing in Cold-rolled Low

1266 Carbon Steels, ISIJ Int. 50 (2010) 7.

1267 [55] M. Moreno, J. Teixeira, G. Geandier, J.-C. Hell, F. Bonnet, M. Salib, S. Allain, Real-

1268 Time Investigation of Recovery, Recrystallization and Austenite Transformation during

1269 Annealing of a Cold-Rolled Steel Using High Energy X-ray Diffraction (HEXRD), Metals. 9

1270 (2018) 8. https://doi.org/10.3390/met9010008.

1271 [56] Bouaziz O, Le Corre C, Flow stress and microstructure modelling of ferrite-pearlite

1272 steels during cold rolling, Mater. Sci. Forum. 426-4 (2003) 1399-1404.

1273 https://www.cheric.org/research/tech/periodicals/view.php?seq=1254580.

1274 [57] S. Allain, O. Bouaziz, Microstructure based modeling for the mechanical behavior of

1275 ferrite-pearlite steels suitable to capture isotropic and kinematic hardening, Mater. Sci. Eng.

1276 A. 496 (2008) 329-336. https://doi.org/10.1016/j.msea.2008.06.009.

1277 [58] ASTM E112-96e2. Standard Test Methods for Determining Average Grain Size,

1278 ASTM International, West Conshohocken, PA, 1996. https://doi.org/10.1520/E0112-96E02.

1279 [59] ASTM E562-08. Test Method for Determining Volume Fraction by Systematic

1280 Manual Point Count, ASTM International, West Conshohocken, PA, 2008.

1281 https://doi.org/10.1520/E0562-08.

1282 [60] K. Radwański, Application of FEG-SEM and EBSD Methods for the Analysis of the

1283 Restoration Processes Occurring During Continuous Annealing of Dual-Phase Steel Strips,

1284 Steel Res. Int. 86 (2015) 1379-1390. https://doi.org/10.1002/srin.201400361.

1285 [61] M. Moreno, Mécanismes métallurgiques et leurs interactions au recuit d'aciers ferrito-

1286 perlitiques laminés : caractérisation et modélisation, Université de Lorraine, 2019.

1287 [62] S.A. Saltikov, The Determination of the Size Distribution of Particles in an Opaque 
1288 Material from a Measurement of the Size Distribution of Their Sections, in: H. Elias (Ed.),

1289 Stereology, Springer, Berlin, Heidelberg, 1967: pp. 163-173. https://doi.org/10.1007/978-3$1290 \quad 642-88260-9 \_31$.

1291 [63] J.C. Russ, Practical Stereology, Springer US, 1986. https://doi.org/10.1007/978-11292 4899-3533-5.

1293 [64] S.Y.P. Allain, S. Gaudez, G. Geandier, J.-C. Hell, M. Gouné, F. Danoix, M. Soler, S. 1294 Aoued, A. Poulon-Quintin, Internal stresses and carbon enrichment in austenite of Quenching 1295 and Partitioning steels from high energy X-ray diffraction experiments, Mater. Sci. Eng. A. 1296710 (2018) 245-250. https://doi.org/10.1016/j.msea.2017.10.105.

1297 [65] A.P. Hammersley, S.O. Svensson, M. Hanfland, A.N. Fitch, D. Hausermann, Two1298 dimensional detector software: From real detector to idealised image or two-theta scan, High 1299 Press. Res. 14 (1996) 235-248. https://doi.org/10.1080/08957959608201408.

1300 [66] THE FIT2D HOME PAGE, (n.d.). http://www.esrf.eu/computing/scientific/FIT2D/ 1301 (accessed January 20, 2020).

1302 [67] H.M. Rietveld, Line profiles of neutron powder-diffraction peaks for structure 1303 refinement, Acta Crystallogr. 22 (1967) 151-152.

1304 https://doi.org/10.1107/S0365110X67000234.

1305 [68] J. Rodríguez-Carvajal, Recent advances in magnetic structure determination by 1306 neutron powder diffraction, Phys. B Condens. Matter. 192 (1993) 55-69.

1307 https://doi.org/10.1016/0921-4526(93)90108-I.

1308 [69] J.-W. Lee, P.R. Howell, Microstructural development in non-oriented lamination 1309 steels, J. Mater. Sci. 22 (1987) 3631-3641. https://doi.org/10.1007/BF01161471.

1310 [70] J.-W. Lee, S.W. Thompson, P.R. Howell, Microstructural development in non1311 oriented lamination steels, J. Mater. Sci. 25 (1990) 1699-1710. 
https://doi.org/10.1007/BF01045373.

1313 [71] J.W. Lee, S.W. Thompson, R. Varughese, P.R. Howell, The interaction between

1314 proeutectoid ferrite and austenite during the isothermal transformation of two low-carbon

1315 steels - a new model for the decomposition of austenite, J. Mater. Sci. 28 (1993) 4571-4577.

1316 https://doi.org/10.1007/BF00414244.

1317 [72] Y. Granbom, L. Ryde, J. Jeppsson, Simulation of the Soaking and Gas Jet Cooling in a

1318 Continuous Annealing Line using Dilatometry, Steel Res. Int. 81 (2010) 158-167.

1319 https://doi.org/10.1002/srin.200900097.

1320 [73] M. Ollat, V. Massardier, D. Fabregue, E. Buscarlet, F. Keovilay, M. Perez, Modeling

1321 of the Recrystallization and Austenite Formation Overlapping in Cold-Rolled Dual-Phase

1322 Steels During Intercritical Treatments, Metall. Mater. Trans. A. 48 (2017) 4486-4499.

1323 https://doi.org/10.1007/s11661-017-4231-6.

1324 [74] S.Y.P. Allain, M. Moreno, M. Lamari, H. Zurob, J. Teixeira, F. Bonnet, A Physics-

1325 Based Mean-Field Model for Ferrite Recovery and Recrystallization, Metals. 10 (2020) 622.

1326 https://doi.org/10.3390/met10050622.

1327 [75] V.I. Savran, Y. Van Leeuwen, D.N. Hanlon, C. Kwakernaak, W.G. Sloof, J. Sietsma,

1328 Microstructural Features of Austenite Formation in C35 and C45 alloys, Metall. Mater. Trans.

1329 A. 38 (2007) 946-955. https://doi.org/10.1007/s11661-007-9128-3.

1330 [76] V.I. Savran, S.E. Offerman, J. Sietsma, Austenite Nucleation and Growth Observed on 1331 the Level of Individual Grains by Three-Dimensional X-Ray Diffraction Microscopy, Metall.

1332 Mater. Trans. A. 41 (2010) 583-591. https://doi.org/10.1007/s11661-009-0142-5.

1333 [77] S.E. Offerman, N.H. van Dijk, J. Sietsma, S. Grigull, E.M. Lauridsen, L. Margulies,

1334 H.F. Poulsen, M.T. Rekveldt, S. van der Zwaag, Grain Nucleation and Growth During Phase

1335 Transformations, Science. 298 (2002) 1003-1005. https://doi.org/10.1126/science.1076681. 
1336 [78] J.-O. Andersson, T. Helander, L. Höglund, P. Shi, B. Sundman, Thermo-Calc \&

1337 DICTRA, computational tools for materials science, Calphad. 26 (2002) 273-312.

1338 https://doi.org/10.1016/S0364-5916(02)00037-8.

1339 [79] M.G. Mecozzi, C. Bos, J. Sietsma, A mixed-mode model for the ferrite-to-austenite

1340 transformation in a ferrite/pearlite microstructure, Acta Mater. 88 (2015) 302-313.

1341 https://doi.org/10.1016/j.actamat.2015.01.058.

1342 [80] M. Ollat, M. Militzer, V. Massardier, D. Fabregue, E. Buscarlet, F. Keovilay, M.

1343 Perez, Mixed-mode model for ferrite-to-austenite phase transformation in dual-phase steel,

1344 Comput. Mater. Sci. (2018) 9.

1345 [81] B. Zhu, M. Militzer, Phase-Field Modeling for Intercritical Annealing of a Dual-Phase

1346 Steel, Metall. Mater. Trans. A. 46 (2015) 1073-1084. https://doi.org/10.1007/s11661-014-

1347 2698-y.

1348 [82] F. Huyan, J.-Y. Yan, L. Höglund, J. Ågren, A. Borgenstam, Simulation of the Growth

1349 of Austenite from As-Quenched Martensite in Medium Mn Steels, Metall. Mater. Trans. A.

135049 (2018) 1053-1060. https://doi.org/10.1007/s11661-018-4497-3.

1351 [83] A. Roósz, Z. Gácsi, E.G. Fuchs, Isothermal formation of austenite in eutectoid plain

1352 carbon steel, Acta Metall. 31 (1983) 509-517. https://doi.org/10.1016/0001-6160(83)90039-1. 

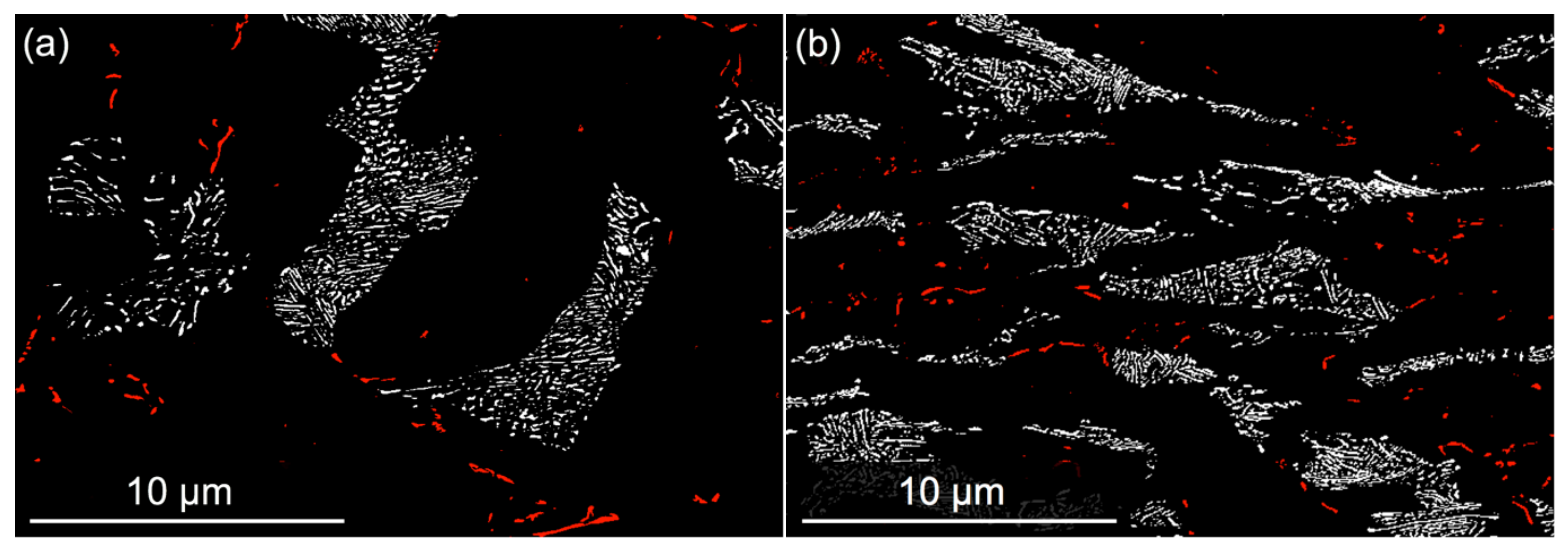

Figure 17. SEM micrographs treated by image analysis representative of the hot-rolled (a) and 1358 cold-rolled (b) microstructures. The ferrite is represented in black, the pearlitic cementite in 1359 white and the isolated carbides in red. 


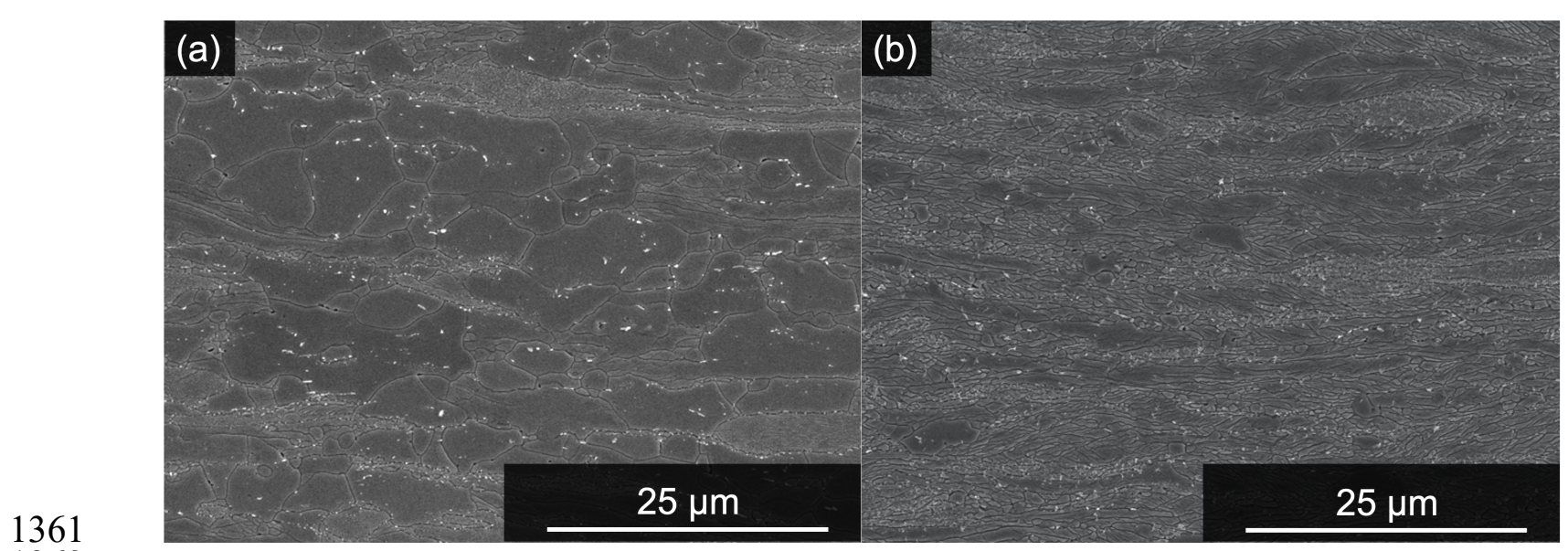

1362
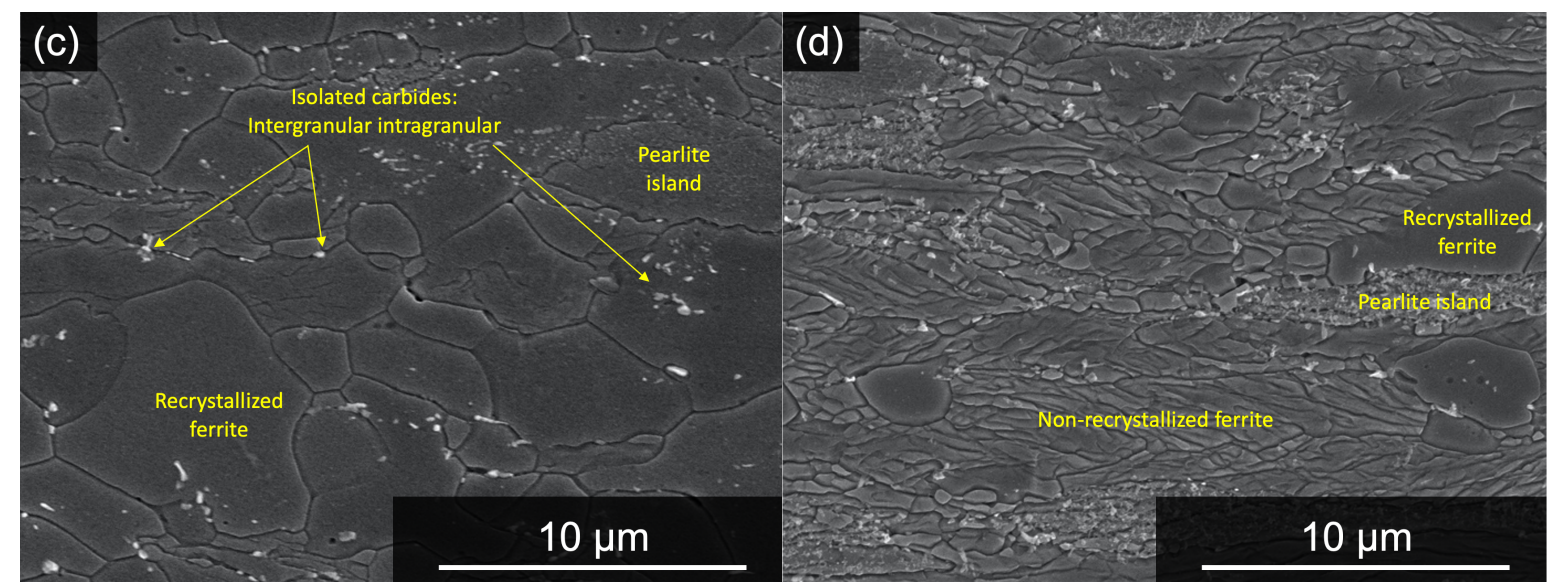

1364

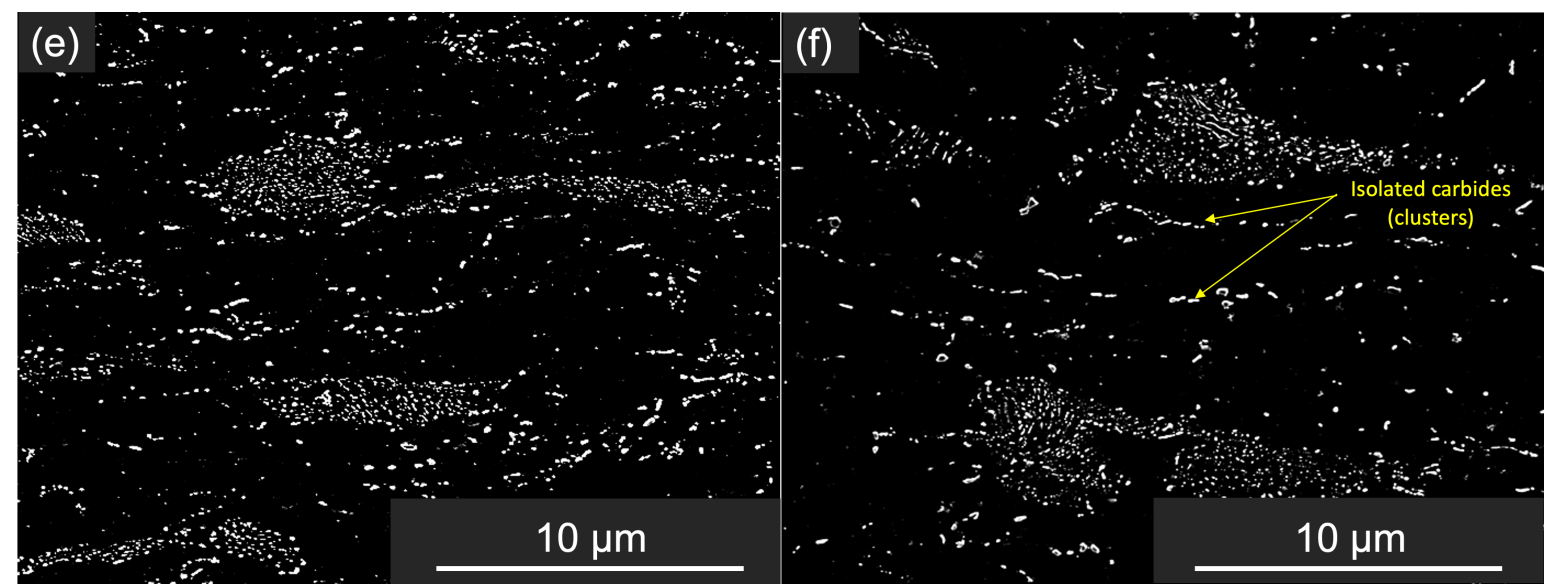

Figure 18. SEM micrographs representative of the microstructure after heating to a,c,e) $700^{\circ} \mathrm{C}$ at $\left.3^{\circ} \mathrm{C} . \mathrm{s}^{-1} ; \mathrm{b}, \mathrm{d}, \mathrm{f}\right) 720^{\circ} \mathrm{C}$ at $30^{\circ} \mathrm{C} . \mathrm{s}^{-1}$. Figures $\mathrm{c}$ and $\mathrm{d}$ correspond to views at higher magnification of $a$ and $b$. Figures e and $f$ have been threshold to reveal carbide microstructures in both cases (carbides in bright contrast). 


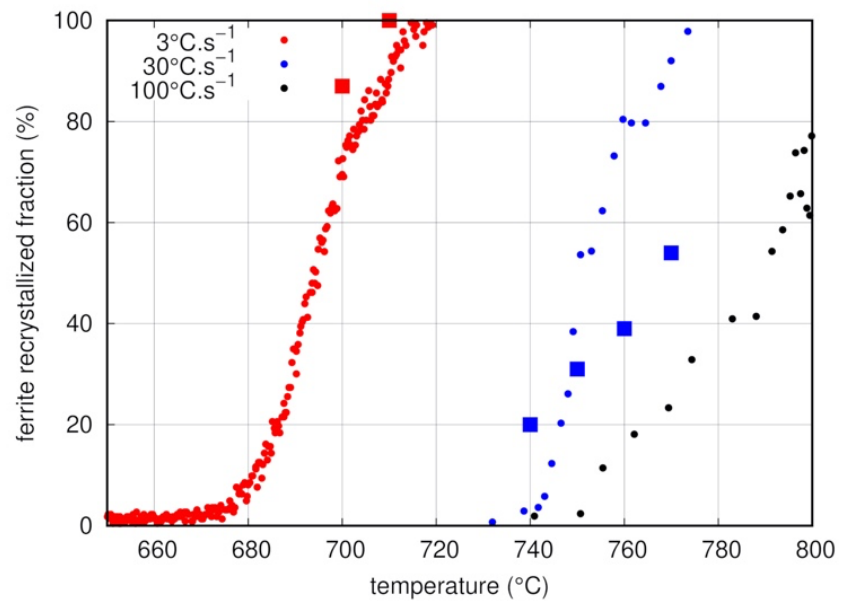

Figure 19. Fraction of recrystallized ferrite as a function of the temperature during heating at 3,30 or $100^{\circ} \mathrm{C} \cdot \mathrm{s}^{-1}$. Dots: HEXRD, squares: SEM at $30^{\circ} \mathrm{C} \cdot \mathrm{s}^{-1}$ or EBSD at $3^{\circ} \mathrm{C} \cdot \mathrm{s}^{-1}$. (In the SEM analyses, the pearlitic ferrite was excluded).

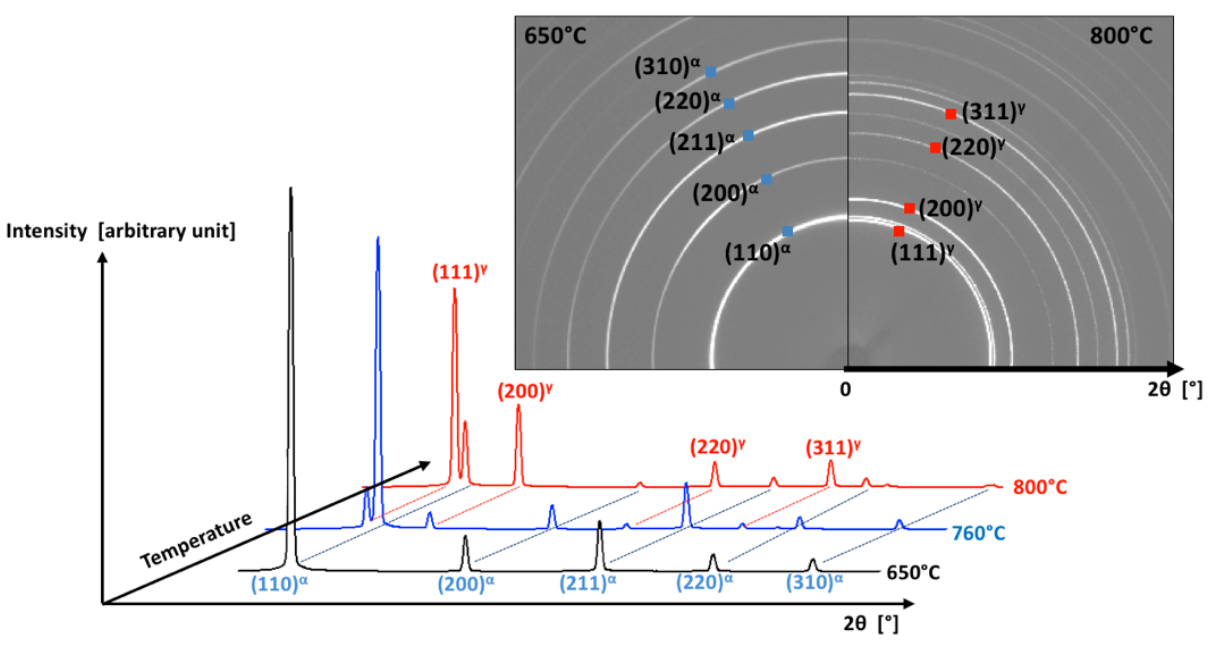

Figure 20. 2D Debye-Scherrer rings recorded at 650 and $800^{\circ} \mathrm{C}$ during heating at $3^{\circ} \mathrm{C}^{-1}{ }^{-1}$.
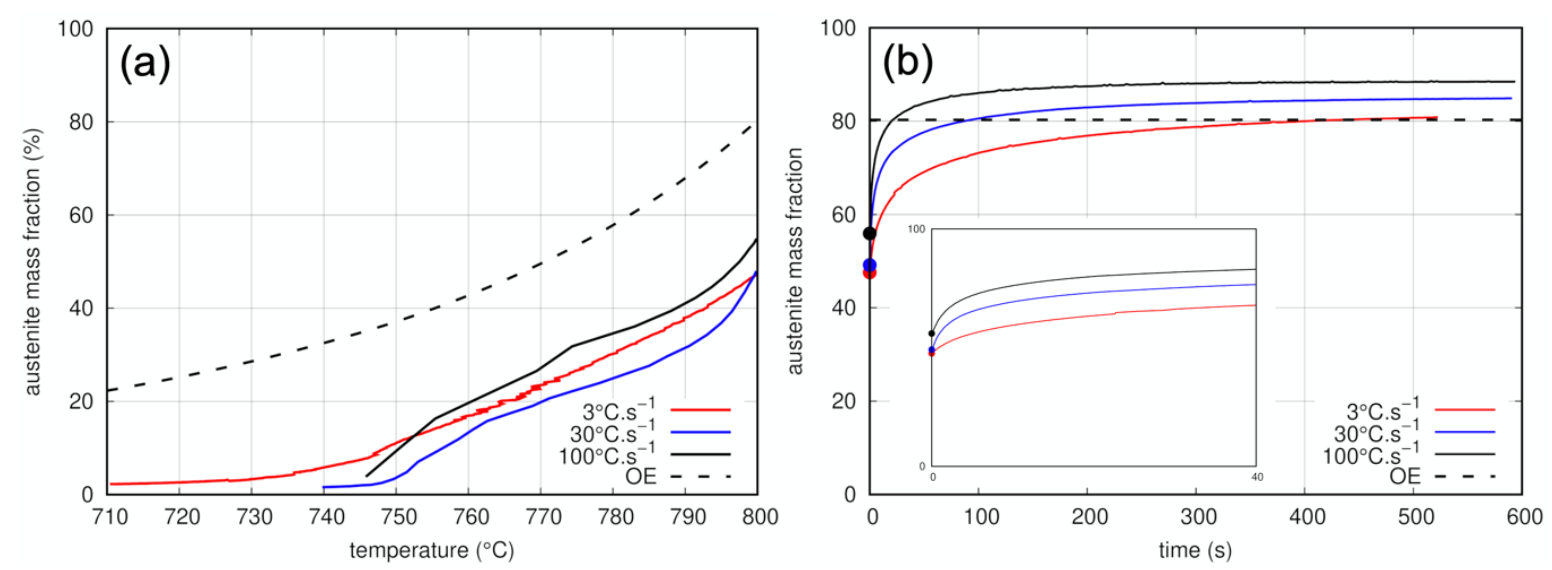

Figure 21. Austenite mass fraction as a function of a) temperature during heating; b) time during isothermal annealing at $800^{\circ} \mathrm{C}$ (zoom on first stages in the insert). Time scale starts at the beginning of the isothermal annealing in $b$ ). The dots indicate the austenite fraction at the start of the isothermal annealing. 

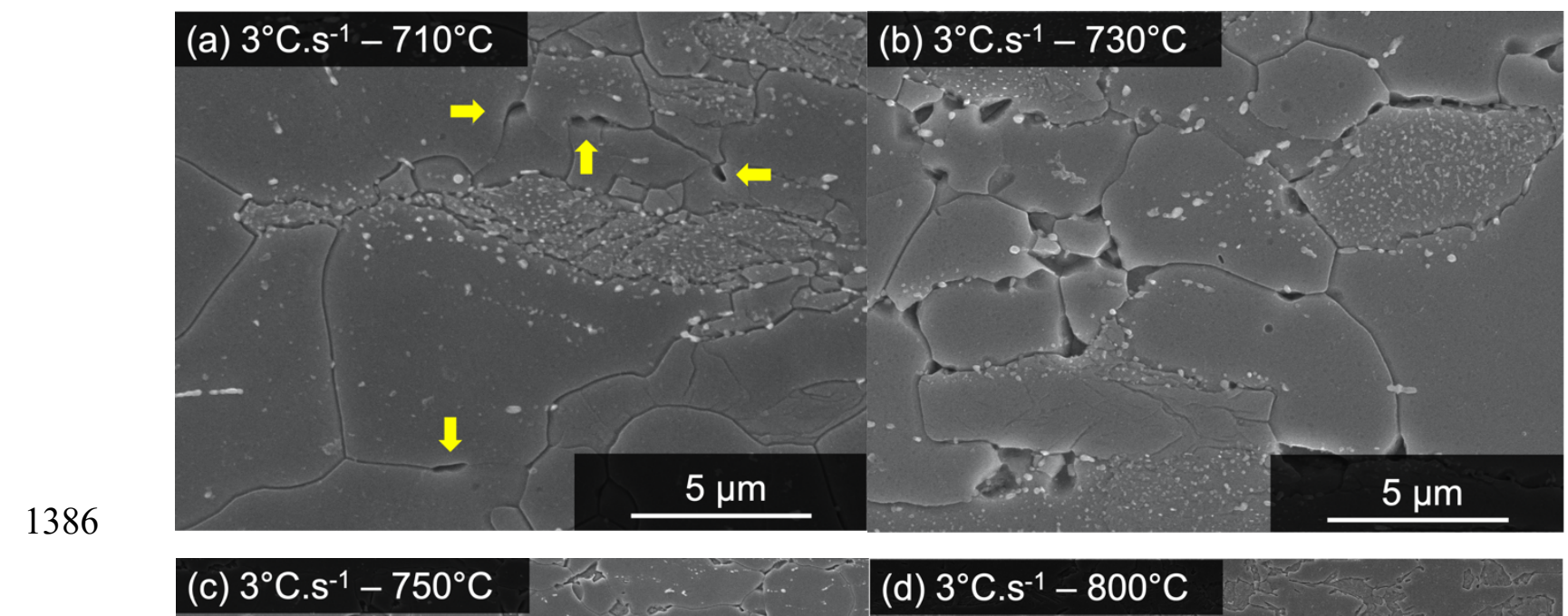

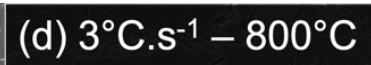

Figure 22. SEM observations (Dino etching) of the microstructure after heating at $3{ }^{\circ} \mathrm{C} \cdot \mathrm{s}^{-1}$ followed by quench up to a) $710^{\circ} \mathrm{C}$; b) $730^{\circ} \mathrm{C}$; c) $750^{\circ} \mathrm{C}$; d) $800^{\circ} \mathrm{C}$. In a), the arrows show the 1390 first grains of austenite.

1391

1392

1393

1394

1395

1396

1397

1398

1399

1400

1401

1402 

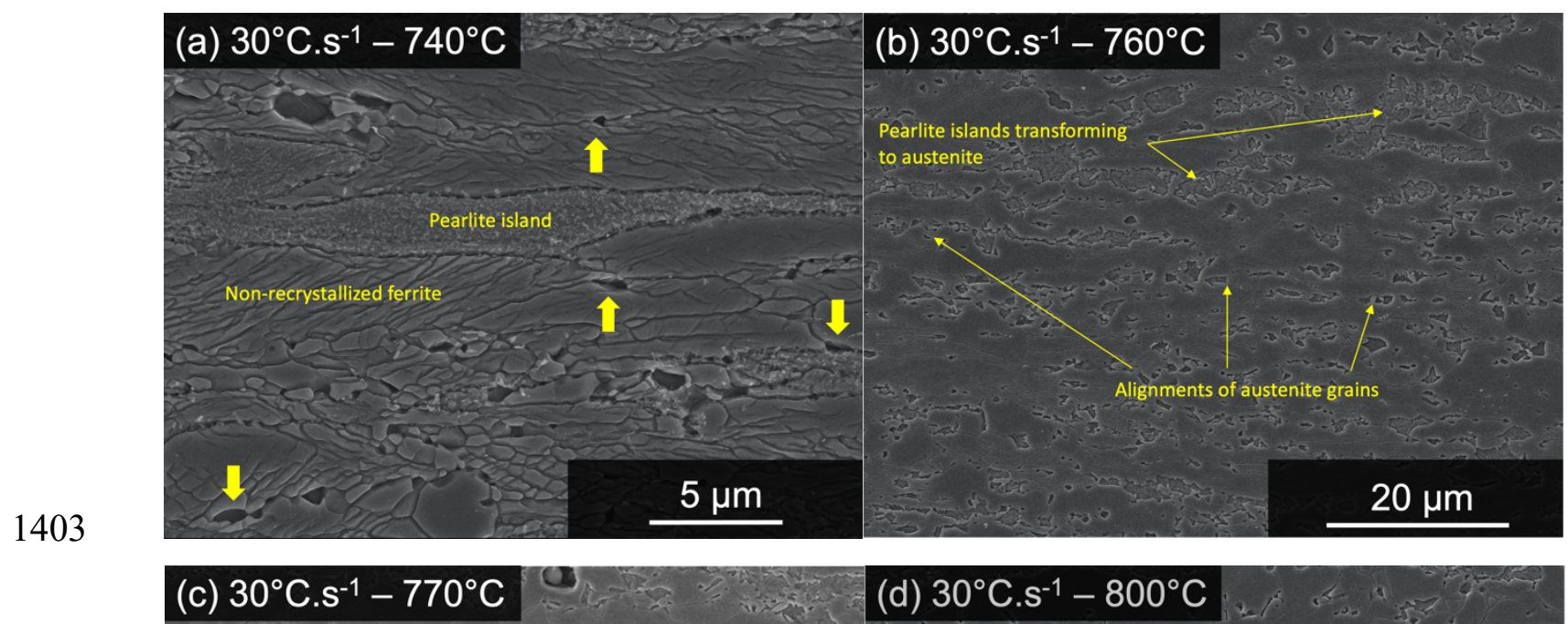

(d) $30^{\circ} \mathrm{C} . \mathrm{s}^{-1}-800^{\circ} \mathrm{C}$

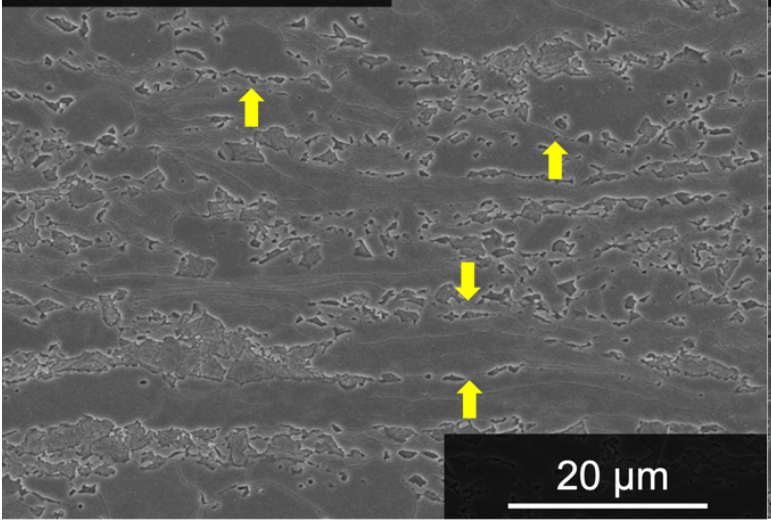

\section{(d) $30^{\circ} \mathrm{C} . \mathrm{s}^{-1}-800^{\circ} \mathrm{C}$}

Figure 23. SEM observations (Dino etching) of the microstructure after heating at $30^{\circ} \mathrm{C} . \mathrm{s}^{-1}$ followed by quench up to a) $740^{\circ} \mathrm{C}$; b) $760^{\circ} \mathrm{C}$; c) $770^{\circ} \mathrm{C}$; d) $800^{\circ} \mathrm{C}$. The arrows indicate: first austenite grains in (a); alignments of austenite grains at the boundaries of elongated recrystallized ferrite grains in (c).

Figure 24. SEM observations (Dino etching) of the microstructure after heating up to $800^{\circ} \mathrm{C}$ and isothermal annealing for $600 \mathrm{~s}$. a) $3^{\circ} \mathrm{C} \cdot \mathrm{s}^{-1}$; b) $30^{\circ} \mathrm{C} \cdot \mathrm{s}^{-1}$. 


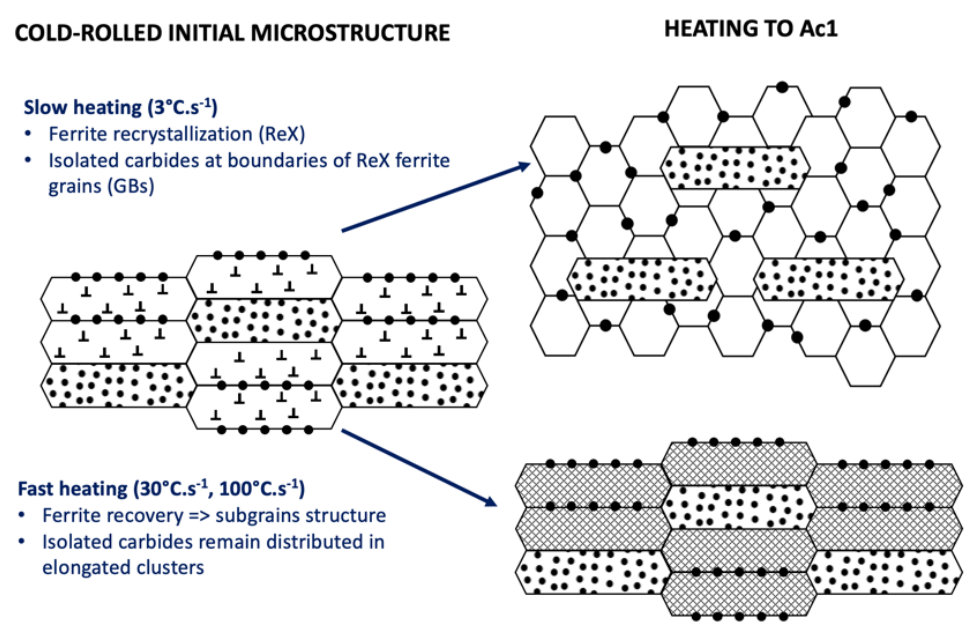

CAPTIONS

Figure 25. Schematic of the austenite morphogenesis depending on the heating rate.
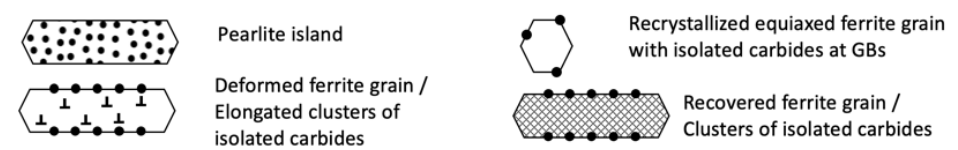

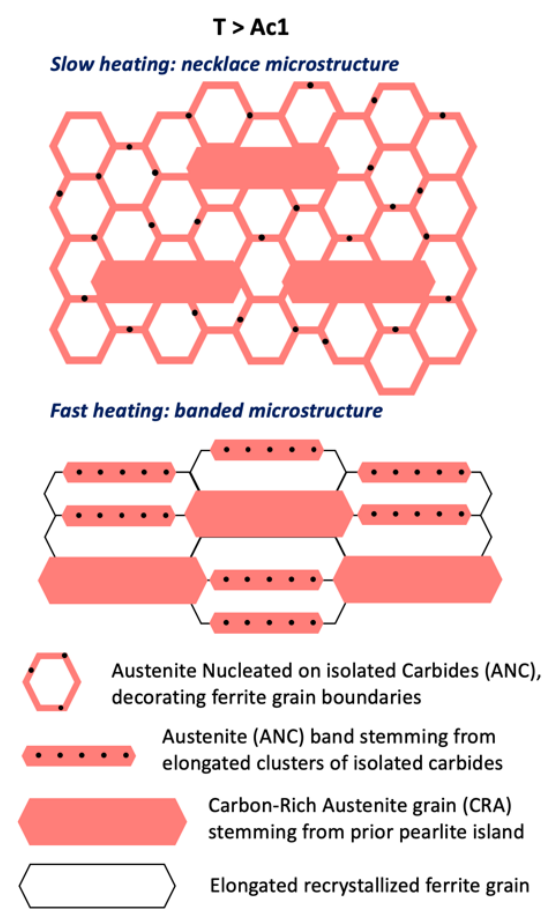

Fast heating: banded microstructure

Austenite Nucleated on isolated Carbides (ANC),

Figure 26. SEM micrographs (Dino etchant) showing austenite grains nucleated on ferrite

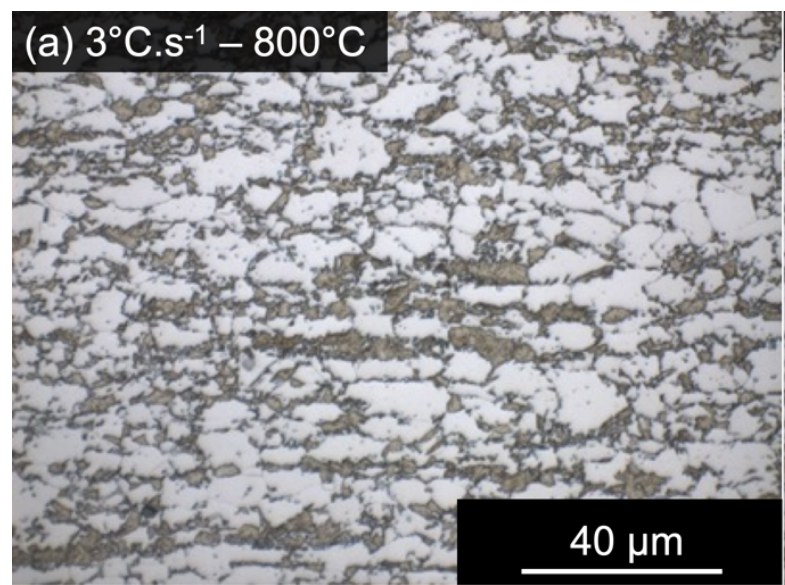

\section{(b) $30^{\circ} \mathrm{C} . \mathrm{s}^{-1}-800^{\circ} \mathrm{C}$}

Figure 27. Optical micrographs of the microstructure after heating up to $800^{\circ} \mathrm{C}$ at a) $3^{\circ} \mathrm{C}^{-1}{ }^{-1}$; b) $30^{\circ} \mathrm{C} \cdot \mathrm{s}^{-1}$. 


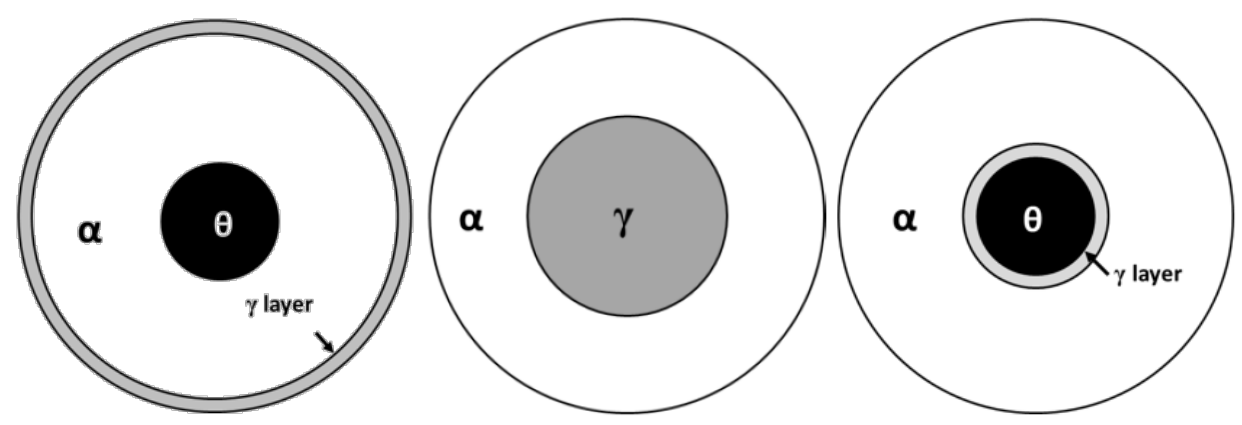

1426

1427 Figure 28. Spherical simulation cells employed in the DICTRA simulations. a) dissolution of a pearlitic cementite carbide (P sub-system); b) Growth of carbon-rich austenite (CRA) grain into ferrite (A sub-system); c) dissolution of an isolated carbide leading to formation of ANC

$\mathbf{T}<\mathbf{A}_{\mathrm{c} 1}$

- Initial microstructure

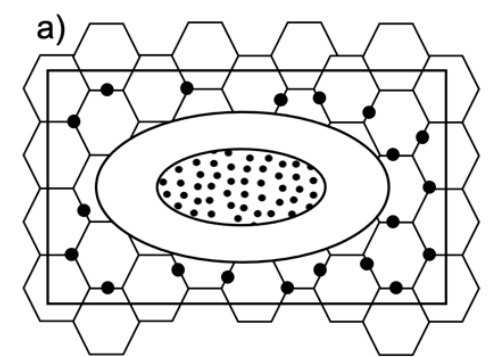

$A_{c 1}<T<T_{\text {end pearlite }}$

1 st stage of austenite transformation, from:

- Pearlite islands (sub-system P)

- Isolated carbides (sub-system I)

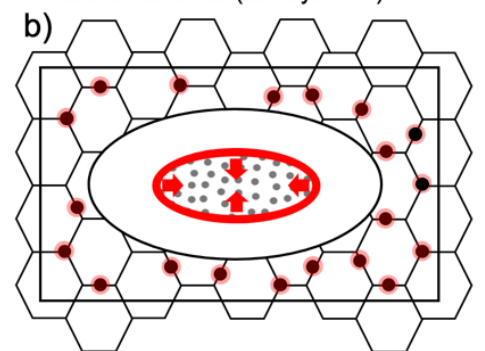

$T>T_{\text {end pearlite }}$

$2^{\text {nd }}$ stage of austenite transformation, from:

- CRA grain growth (sub-system A)

- Isolated carbides (sub-system I)

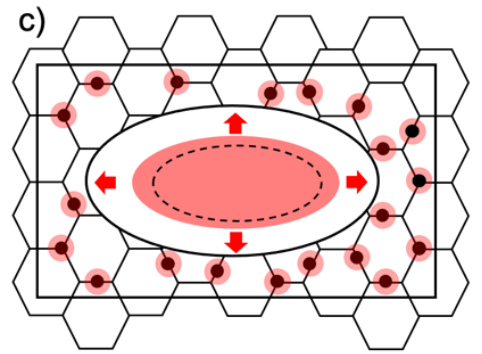

Figure 29. Geometrical representation of the microstructure; two stages of austenite transformation. a) Initial microstructure; b) first stage of austenite transformation; c) second 

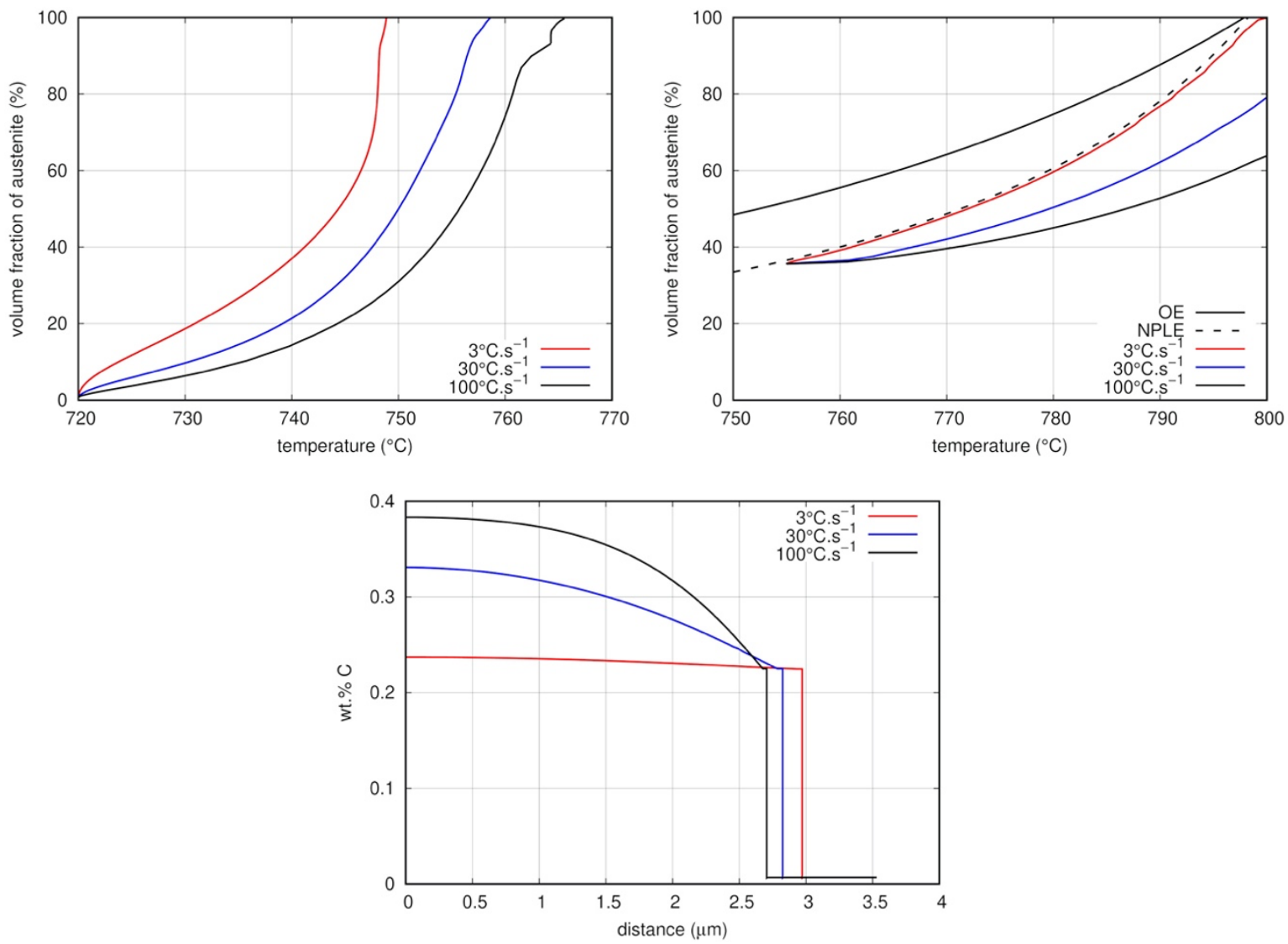

Figure 30. Austenite volume fraction as a function of temperature according to DICTRA simulations inside the simulation cells represented in Figure 12a-b. a) transformation of the pearlite island (sub-system P); b) growth of the CRA grain (sub-system A). OE and NPLE curves represent the austenite volume fraction at equilibrium and after a ferrite to austenite transformation without partition of the $\mathrm{Mn}$; c) carbon concentration profiles at $780^{\circ} \mathrm{C}$ in
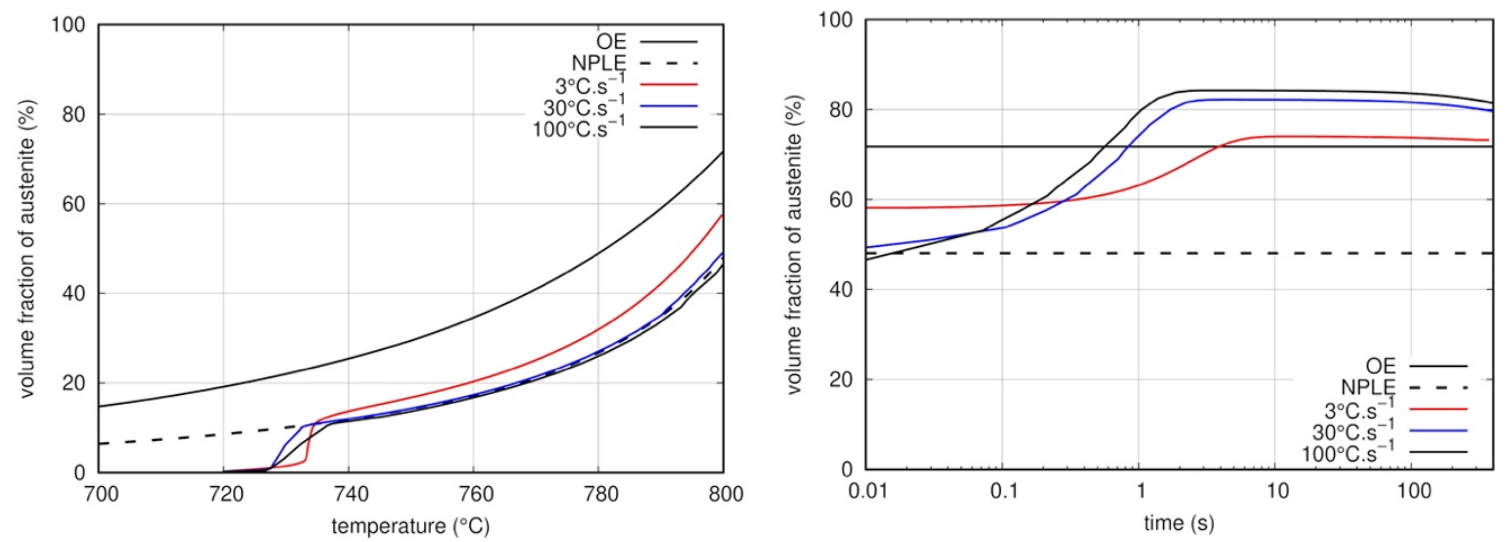

Figure 31. Austenite volume fraction evolution according to DICTRA simulations representative of the isolated carbides dissolution (sub-system I). a) during heating, as a function of temperature; b) during isothermal hold at $800^{\circ} \mathrm{C}$. OE and NPLE curves have the same meaning as in Figure 14. (Values are different because of the different overall carbon 


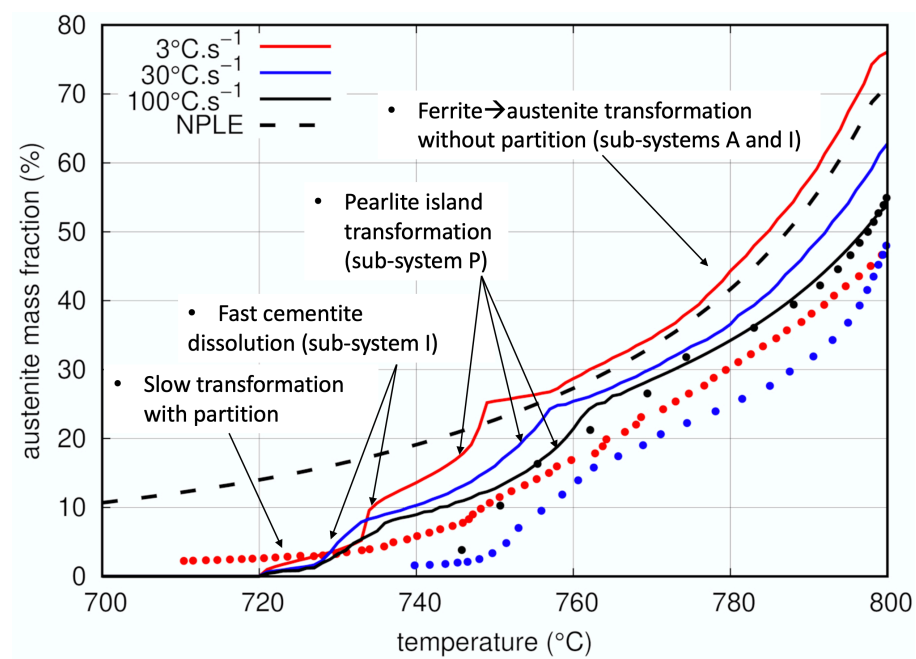

1465 Figure 32. Overall austenite fraction as a function of temperature during heating at 3, 30 and 